\title{
A Theoretical Model for the Formation of Ring Moat Dome Structures: Products of Second Boiling in Lunar Basaltic Lava Flows
}

\author{
Lionel Wilson ${ }^{1,2}$, James W. Head ${ }^{2}$ and Feng Zhang ${ }^{3}$ \\ ${ }^{1}$ Lancaster Environment Centre, Lancaster University, Lancaster, UK \\ ${ }^{2}$ Department of Earth, Environmental and Planetary Sciences, \\ Brown University, Providence, RI 02912 USA \\ ${ }^{3}$ State Key Laboratory of Lunar and Planetary Sciences, \\ Macau University of Science and Technology, Macau, China
}

\author{
Keywords: \\ Ring Moat Dome Structure \\ Lunar basaltic lava \\ Lava flow inflation \\ Second boiling
}

\begin{abstract}
:
Newly documented Ring Moat Dome Structures (RMDSs), low mounds typically several hundred meters across with a median height of $\sim 3.5 \mathrm{~m}$ and surrounded by moats, occur in the lunar maria. They appear to have formed synchronously with the surrounding mare basalt deposits. It has been hypothesized that they formed on the surfaces of lava flows by the extrusion of magmatic foams generated in the flow interiors as the last stage of the eruption and flow emplacement process. We develop a theoretical model for the emplacement and cooling of mare basalts in which the molten cores of cooling flows are inflated during the late stages of eruptions by injection of additional hot lava containing dissolved volatiles. Crystallization of this lava causes second boiling (an increase in vapor pressure to the point of supersaturation due to crystallization of the melt), generating copious quantities of vesicles (magmatic foam layers) at the top and bottom of the central core of the flow. Flow inflation of many meters is predicted to accompany the formation of the foam layers, flexing the cooled upper crustal layer, and forming fractures that permit extrusions of the magmatic foams onto the surface to form domes, with subsidence of the subjacent and surrounding surface forming the moats. By modelling the evolution of the internal flow structure we predict the properties of RMDSs and the conditions in which they are most likely to form. We outline several tests of this hypothesis.
\end{abstract}


45

46

47

48

49

50

51

52

53

54

55

56

57

58

59

60

61

62

63

64

65

66

67

68

69

70

71

72

73

74

75

76

77

78

79

80

81

82

83

84

85

86

87

88

89

90

91

92

93

94

\section{Introduction:}

The volcanic origin of the lunar maria has been known confidently for more than fifty years (see reviews in Head, 1976; Hiesinger and Head, 2006; Spudis, 2016), but new very high-resolution image and altimetry data from the Lunar Reconnaissance Orbiter (LRO) have continued to reveal surprises, including the wide-spread occurrence of features originally detected by Schultz (1976) and Schultz et al. (1976), and now called Ring Moat Dome Structures (RMDSs) (Zhang et al., 2017). More than two thousand of these features were recently documented in numerous maria (Figure 1) (Zhang et al., 2017). Theories proposed for their origin, summarized in Zhang et al. (2017), include emplacement of domes of more viscous magma, extrusions into impact craters billions of years after mare emplacement, squeeze-ups or hornitos formed synchronously with lava flow emplacement, and extrusion of magmatic foams (i.e., lavas with greater than $\sim 70 \%$ vesicularity, Mangan and Cashman, 1996) that developed below a cooling lava flow surface.

The availability of LRO imaging (Robinson et al., 2010) and topographic (Smith et al., 2010) data, together with a better understanding of the ways in which magma is transferred from the lunar mantle to the surface (Wilson and Head, 2017a; Head and Wilson, 2017), and improvements in the analysis of patterns of gas release from lunar magmas (Rutherford et al., 2017; Wilson and Head, 2018a) have prompted recognition of the importance of the formation and extrusion of magmatic foams in shaping lunar volcanic features (Qiao et al., 2017, 2018a, 2018b; Wilson and Head, $2017 b, 2018 b)$. Foam formation without extrusion can be a source of inflation of lunar lavas (Garry et al., 2012; Elder et al., 2017) and a study of an inflated terrestrial lava has shown that neglect of the consequences of this can be a major source of error in deducing lava eruption characteristics from final deposit morphology observed by remote sensing (Kolzenburg et al., 2018). We use these various developments to assess the potential environment of RMDS formation, describing the basic characteristics of these features that must be accounted for by any theory of their origin. We then develop a model of the dynamics of mare lava flow emplacement and use this to explore in detail the hypothesis that RMDS formation involves the production of magmatic foams and their extrusion through a chilled upper lava flow boundary layer. We conclude with predictions of the internal structures of RMDSs and propose tests that can be undertaken with future observations of the global distribution and characteristics of RMDSs.

\section{Characteristics of Ring Moat Dome Structures:}

Following the initial recognition of these features (Schultz et al., 1976; Schultz, 1976), Zhang et al. (2017) used new LRO Lunar Reconnaissance Orbiter Camera (LROC) data to analyze and characterize the distribution and morphology of RMDSs, and digital terrain models (DTMs) to document their morphometry (Zhang et al., 2017, 2018a, 2018b). RMDSs are generally circular in shape (Figure 1), have a dome-like morphology with a surrounding moat, and are often concentrated in clusters (Zhang et al., 2017. RMDSs have only been found in certain mare regions (Figure $2 b$ ) and have a mineralogy similar to that of the surrounding lava, suggesting no major compositional difference between the RMDSs and the surrounding maria (Zhang et al., 2017). Detailed morphometric measurements (Figure 2c) using DTMs showed that of the 512 RMDSs measured, the mound diameters range from $68-645 \mathrm{~m}$ 
(median $192 \mathrm{~m}$ ), the mound heights range from $0.38 \mathrm{~m}$ to $13.4 \mathrm{~m}$ (median $3.41 \mathrm{~m}$ ), the height-to-diameter ratios are small (0.01-0.04) and the slopes are very gentle $\left(1.5-5^{\circ}\right)$, increasing toward the mound margins (Zhang et al. 2017). Theories of RMDS origin must be able to account for these major characteristics of size, shape, morphology and morphometry, clustering, and mineralogical similarity to the adjacent maria in which they are located. We therefore begin by assessing the mechanisms by which the underlying lava flows were emplaced.

\section{Emplacement of mare lava flows:}

Mafic eruptions on the Earth and Moon differ in that the source depths of lunar basalts are an order of magnitude greater than is typical on Earth (Hess, 2000; Grove and Krawczynski, 2009). The characteristics of large mare lava flows can be modeled in terms of the processes that must occur when giant dikes rise from the deep mantle and interact with the crust (Wilson and Head, 1983; 2017a; Head and Wilson, 1992). The low viscosity of lunar basalts (Murase and McBirney, 1970), coupled with the great widths of dikes of the size needed to explain the erupted volumes of large mare flows (Head and Wilson, 2018; Wilson and Head, 2017a), implies very high rise speeds for the dikes as they approach the surface. The high initial rise speed of a dike, coupled with its deceleration as it progressively loses buoyancy on penetrating the crust and is eventually forced to decrease in width due to compressive tectonic forces, leads to a predictable pattern of magma discharge rate as a function of time (Wilson and Head, 2018a). Typical examples of dikes producing long (up to several hundred $\mathrm{km}$ ), large-volume (200-400 $\mathrm{km}^{3}$ ) flows (Head and Wilson, 2017) involve initial dense rock equivalent volume fluxes, $F$, of $\sim 10^{6} \mathrm{~m}^{3} \mathrm{~s}^{-1}$ decreasing over the course of a few days to $10^{5} \mathrm{~m}^{3} \mathrm{~s}^{-1}$ and then decreasing more slowly over some tens of days to $\sim 10^{4} \mathrm{~m}^{3} \mathrm{~s}^{-1}$ (Wilson and Head, 2017a). The lava flows leaving the vent are initially turbulent and remain so until $F$ decreases below $\sim 3 \times 10^{4} \mathrm{~m}^{3} \mathrm{~s}^{-1}$. Calculations of the dynamics of emplacement of such flows (Wilson and Head, 2018b) can be used to predict the initial thickness, $D_{\mathrm{f}}$, and mean speed, $U_{\mathrm{f}}$, of the flow as a function of total volume flux $F$ and the flow width $W_{\mathrm{f}}$. Figure 3 shows these variations for a flow erupted onto the present-day mean surface slope of SW Mare Imbrium, 0.086 degrees. $F$ is predicted to decrease by $\sim 2$ orders of magnitude with time whereas $W_{\mathrm{f}}$ decreases much less, typically by a factor of $\sim 3$ from $\sim 15 \mathrm{~km}$ to $\sim 5 \mathrm{~km}$. A curve is shown on each part of Figure 3 indicating how $D_{\mathrm{f}}$ and $U_{\mathrm{f}}$ at the vent would change with time during a specific eruption: the label "A" in Figure 3 marks the values at the start of the eruption and the label "B" marks values at the end.

As a flow advances, it loses heat at all of its margins; however, as long as it remains turbulent, heat loss is dominated by radiation at the upper flow surface (Head and Wilson, 2018). The temperature decrease causes crystallization, with latent heat release helping to offset heat losses. The presence of the resulting solids in the flow increases the bulk viscosity and introduces a yield strength. The consequent nonNewtonian rheology can be modeled as that of a Bingham plastic (Wilson and Head, 2018b), requiring evaluation of both a Reynolds number and a Hedström number to characterize the motion. Turbulence continues as long as the Reynolds number remains greater than a critical value that is itself a function of the Hedström number (Skelland, 1967). Once turbulence has vanished, the flow quickly develops a cool upper surface, and heat loss from that surface becomes limited by conduction through the growing crust. As a consequence of the previous turbulence, the lava between the 
growing thermal boundary layers is essentially isothermal, so that the temperature and rheology of the lava in the core of the flow now change very much more slowly. It is easy to show by evaluating the Grätz number, a measure of the extent of the penetration of cooling into the laminar flow (Pinkerton and Wilson, 1994), that flows of the scale of the large mare lavas ultimately stop for a combination of reasons, not only as a result of cooling (Wilson and Head, 2017a; Head and Wilson, 2018). As the flow advances, the thicknesses of the cooling upper and lower thermal boundary layers increase. However, the upper part of the lava in the central channel flows as a rigid unsheared plug as a result of the presence of the yield strength, and we find that the plug thickness is in all cases greater than the thickness of the upper thermal boundary layer. The flow stops advancing when the growing lower cooling layer and the thickening plug meet, so that no part of the lava can undergo shearing. For a typical mare basalt, the core of the flow, between the upper and lower thermal boundary layers, will have cooled through $30 \%$ of the interval between its liquidus and solidus, will contain $30 \%$ crystals, will have a bulk viscosity of $12 \mathrm{~Pa} \mathrm{~s}$, and a yield strength of $175 \mathrm{~Pa}$.

Although there is some reduction in advance speed and increase in thickness of the front of a flow as it moves away from the vent, this is partly compensated by the fact that the eruption rate is decreasing with time, and as a consequence the distal parts of the large lunar mare lava flow deposits are expected to have thicknesses comparable to the thicknesses that the lava forming them had on leaving the vent. The consequence of this is that the flow thicknesses at the points labeled "A" and "B" in Figure 3 can be regarded, to a good approximation, as being the flow thickness in the proximal, $D_{\mathrm{p}}$, and distal, $D_{\mathrm{d}}$, parts, respectively, of a given lava flow deposit. For this example, by the time the lava at the $D_{\mathrm{d}}=14 \mathrm{~m}$ high flow front, erupted from an initially $15 \mathrm{~km}$ long fissure, has reached its furthest extent from the vent, the vent will be erupting a stream of lava approximately $D_{\mathrm{p}}=4 \mathrm{~m}$ in thickness from a $3 \mathrm{~km}$ long fissure.

\section{Characteristics of mare lava flows:}

In order to understand the possible subsequent development of large mare lava flow fields produced under the conditions shown in Figure 3 it is necessary to define the internal structure of the lava in the various parts of such a field (Head and Wilson, 2018). Lunar magmas are erupted into a vacuum, and the presence of even very small amounts of volatiles can ensure that explosive activity occurs (Wilson and Head, 1981). Based on direct analysis of returned pyroclast samples and high-pressure laboratory experiments on samples with the same composition, lunar magma volatiles are found to be dominated by up to $\sim 1000 \mathrm{ppm}$ CO released mainly at depths between 500 and $50 \mathrm{~km}$ with an admixture of at least several hundred $\mathrm{ppm} \mathrm{H}_{2} \mathrm{O}$ and sulfur species released at depth less than $500 \mathrm{~m}$ (Rutherford et al., 2017). The expansion of gas bubbles nucleating with initial diameters of $\sim 10 \mu \mathrm{m}$ causes close packing to occur when the bubbles have grown to a few hundred microns, and the magma is then fragmented into sub-mm size pyroclastic droplets to emerge from the vent in a hawaiian-style fire fountain or curtain-of-fire eruption fed by a lava volume flux of $\sim 10^{6} \mathrm{~m}^{3} \mathrm{~s}^{-1}$ (Wilson and Head, 2017a). The combination of small droplet size and large droplet numbers in the fountains causes them to be optically dense, i.e., other than at the very outermost edges of the fountain, droplets obscure one another's ability to radiate heat. As a result, droplets fall to the ground at magmatic temperatures and 
coalesce into a lava lake that feeds lava flows. After they leave the immediate vicinity of the vent, these droplets are exposed to a hard vacuum. Also, the time they spend in flight is greater than it would be on Earth for a given eruption speed by a factor of $\sim 6$ because of the low acceleration due to gravity on the Moon. As a result, the droplets should very efficiently lose almost all of their residual volatiles. The lava flows generated from the earliest phase of an eruption are therefore expected to have an extremely low vesicularity, and it is these flows that form the distal parts of the resulting flow field.

By the end of an eruption the magma volatile inventory will not have changed significantly, but the erupted volume flux $F$ will have decreased dramatically to $\sim 10^{4}$ $\mathrm{m}^{3} \mathrm{~s}^{-1}$. The simulations of lunar fire fountains given by Wilson and Head (2017a) show that, despite this reduction in $F$, if a stable fire fountain exists it will still be retaining almost all of its heat and feeding hot, vesicle-free flows. However, the reduction in $F$ with time implies a reduction in the rise speed, $U_{\mathrm{d}}$, of the magma rising through the dike feeding the eruption, and this has important consequences for the eruption style. Gas bubbles nucleating in rising magma grow from their initial diameters of $\sim 10 \mu \mathrm{m}$ as volatiles in the surrounding liquid diffuse into them, and also expand due to the decreasing pressure. As the bubbles grow in size their buoyancydriven rise speed through the magmatic liquid increases, but as long as that speed is much less than the rise speed of the magma itself through the dike, bubbles are effectively uniformly distributed in the magma.

If the magma rise speed $U_{\mathrm{d}}$ becomes small enough this is no longer true; larger, earlier-nucleated bubbles can overtake later-formed, smaller bubbles and coalescence can occur, leading to an increase in rise speed of the new, even larger bubbles. In the extreme case of very small values of $U_{\mathrm{d}}$, giant bubbles called slugs form, filling the conduit apart from a thin veneer against the walls, and absorbing almost all of the smaller bubbles in the liquid (Suckale et al., 2010; Pering and McGonigle, 2018). The lava lake around the vent is now no longer fed by pyroclastic droplets falling from above but instead is punctured by slugs emerging from depth and throwing off clots of magma as they burst through the lake surface in strombolian explosions (Blackburn et al., 1976). Wilson and Head (1981) showed that the transition between intermittent strombolian and relatively steady hawaiian explosive activity on the Moon would have occurred at magma rise speeds between $\sim 0.1 \mathrm{~m} \mathrm{~s}^{-1}$, low enough to encourage gas bubble coalescence, and $0.5 \mathrm{~m} \mathrm{~s}^{-1}$, fast enough to inhibit coalescence. The speed $U_{\mathrm{d}}$ is related to the magma volume flux $F$ via the product $F=U_{\mathrm{d}} W L$ where $W$ and $L$ are the horizontal width and length, respectively, of the feeding dike. For the Moon, Head and Wilson (2017) estimate typical values of $\sim 10 \pm 5 \mathrm{~km}$ for $L$ and $9 \pm 4 \mathrm{~m}$ for $W$. As a result, all eruptions with $F$ greater than $10^{5} \mathrm{~m}^{3} \mathrm{~s}^{-1}$ are expected to be hawaiian, and all with $F$ less than $\sim 3 \times 10^{3} \mathrm{~m}^{3} \mathrm{~s}^{-1}$ are expected to be strombolian. The transition between these eruption styles for fissure lengths in the $5-15 \mathrm{~km}$ range occurs for values of $F$ between $\sim 4 \times 10^{4}$ and $2 \times 10^{4} \mathrm{~m}^{3} \mathrm{~s}^{-1}$. Thus, at some stage late in a typical eruption, when $F$ has decreased to less than $\sim 10^{4} \mathrm{~m}^{3} \mathrm{~s}^{-1}$, the activity will have become strombolian.

The lava flows emplaced during strombolian activity on the Moon will have distinctive characteristics. Recall that these flows are fed by the outflow from the vent lava lake of magma that has been smeared against the walls of the dike by rising gas slugs and has then risen into the base of the lava lake. Experiments by Llewellen 
et al. (2012) show that typically $84 \%$ of the initial volatiles would have been removed from this magma, so that initial volatile contents as large as 1000 and 2000 ppm would have been reduced to 160 and 320 ppm, respectively. This lake- and flowfeeding liquid will contain mainly small bubbles of the gas species that exsolved at low pressures in the upper $\sim 500 \mathrm{~m}$ of the dike after the last passage of a slug and have grown as they approach and enter the lake. Since water is the main volatile released at less than $500 \mathrm{~m}$ depth (Rutherford et al., 2017) we use its physical properties in the illustrations that follow. In general, the pressure, $P_{\mathrm{b}}$, in the bubbles will be controlled by the surface tension, $\sigma$, of the gas-liquid interface and will be of order $(2 \sigma / \phi)$ where $\phi$ is the bubble diameter and $\sigma=\sim 0.37 \mathrm{~J} \mathrm{~m}^{-2}$ (Mangan and Cashman, 1996). For bubbles nucleating with $\phi=10 \mu \mathrm{m}, P_{\mathrm{b}}=74 \mathrm{kPa}$. If these bubbles nucleate at 500 $\mathrm{m}$ depth and rise to within $0.1 \mathrm{~m}$ of the surface they will have grown to $\sim 170 \mu \mathrm{m}$ and will have internal pressures of $\sim 4 \mathrm{kPa}$; at $1 \mathrm{~cm}$ depth the diameters are $\sim 370 \mu \mathrm{m}$ and the pressures $\sim 2 \mathrm{kPa}$.

It can readily be shown that for the up to $\sim 1000 \mathrm{ppm}$ mainly water contents of lunar magmas, bubbles within a few meters of the surface will, if stable, constitute an extremely vesicular foam (Wilson and Head, 2017b). At the surface of the lake, gas bubbles may explode into the overlying vacuum. In theory, bubbles in contact with a vacuum should have expanded to an infinite size so that the pressure within them is zero, and the only reason for their collapse is the drainage of liquid through the thin films between the bubbles. In practice the system is complex because the surface of the lake will be radiating heat to the vacuum and so the liquid films will rapidly solidify, adding a mechanical strength to the system. Fielder et al. (1967) exposed liquid basalts to low pressures and found that gas bubbles ceased to expand and formed a $>90 \%$ vesicular foam of sub-mm sized bubbles when the ambient pressure fell below $3 \mathrm{kPa}$; while this appears to be generally in agreement with the above discussion, the pre-melting volatile (presumably mostly water) contents of these basalts were not measured, and radiative cooling may have influenced the behavior of the small samples used.

As a result, in modeling foam lavas of this kind, Wilson and Head (2018b) adopted the conservative assumption that a wave of instability would spread down into a lava lake containing foams of this kind until the accumulated debris of broken bubble walls and collapsed interstitial liquid films reached a great enough thickness that its weight exerted a high enough pressure to reduce the vesicularity to $65 \%$, a value commonly observed in pumiceous pyroclasts and similar to the value 0.69 suggested by Jaupart and Vergniolle (1989). Assuming a porosity of $30 \%$ for the debris layer material, debris layer thicknesses of $\sim 0.5,1.7$ and $3.5 \mathrm{~m}$ were found for initial magma water contents of 100, 200 and $300 \mathrm{ppm}$. Beneath the debris layer, the vesicularity of the foam is controlled by the overlying pressure, both as regards its effect on the volume of bubbles and on the exsolution of volatiles: a high enough pressure will ensure that none of the water is exsolved. Figure 4 shows the resulting vesicularity as a function of depth for the above three water contents in a flow with the $4 \mathrm{~m}$ thickness expected near the end of a mare basalt eruption. The implications of this figure are that if the residual water content of the magma is sufficiently small, most of it remains in solution in the lower part of the lava flow. Thus, in Figure 4a, for 100 ppm remaining, $90 \%$ of the flow retains dissolved water; in Figure 4b, for 200 ppm remaining, a little less than half of the flow does so; and in Figure 4c, for 300 ppm volatiles remaining, none of the flow retains water and the flow consists only of 
a debris layer overlying a very vesicular layer. Figure $4 \mathrm{~b}$ defines the depth to the top of the lava layer still containing dissolved water, $D_{\mathrm{t}}$, and the thickness of that layer, $D_{\mathrm{w}}$, for use in Section 5.1, and indicates the progressive changes with increasing depth within the flow.

\section{Proposed RMDS formation mechanism:}

\subsection{Flow inflation:}

The presence towards the end of the eruption of a stationary mare lava flow field of volatile-poor, non-vesicular lava in the distal part of the field and the availability of lava still containing dissolved water being erupted into the proximal part of the field strongly suggests a mechanism for producing RMDSs. The process is closely related to the behavior inferred for many lava fields on Earth (Aubele et al., 1988; Hon et al., 1994; Self et al., 1996, 1998; Thordarson and Self, 1998): the relatively rapid emplacement of long flows, followed by the injection of later magmatic liquid into these stationary flows causing an initial phase of inflation. Subsequently, and on a time scale of weeks after all lava motion has ceased, continued cooling of the now composite flow interior causes crystallization. Volatiles still present in the injected lava behave incompatibly and are not incorporated into the crystals, and so become increasingly concentrated in the residual liquid phase, rapidly becoming supersaturated and causing second boiling, i.e. rapid additional gas release, producing very vesicular foam layers within the flow and leading to segregation structures. Second boiling has been invoked to explain some of the internal morphology of various types of lava flows on Earth (Morey, 1922; Sisson and Bacon, 1999; Beresford et al., 2002), including flood-basalts (Self et al., 1996). The process will be more dramatic on the Moon where low acceleration due to gravity and absence of atmospheric pressure encourage release of greater amounts of volatiles and greater expansion of them after release. We propose that it is the escape of the internallyformed foam layers onto the surface of the flow that forms the RMDSs. The key requirement is not just the inflation of the initial flow deposits, it is the presence of still-dissolved volatiles in the lava that is being injected to cause the inflation (see Figure 5 for details), and the forced exsolution of these volatiles as the lava cools.

We take as our starting point the flow field development represented by Figure 3. Vesicle-free distal flows $D_{\mathrm{d}}=14 \mathrm{~m}$ thick produced by the high erupted volume flux early in the eruption are connected to proximal flows $D_{\mathrm{p}}=4 \mathrm{~m}$ thick generated just after the change to laminar motion in the lava leaving the fissure vent produces flows having structural profiles like those in Figure 4. Although there is continuity between the hot interiors of the lava at all distances from the vent, we do not think that it is likely that all of the proximal lava will be involved in the inflation of the distal flows. The fragmental layer at the top of the proximal flows is likely to be easily sheared, but the $<65 \%$ vesicular layer immediately beneath it will have a higher viscosity than the vesicle-free lava at the base which still contains dissolved water. It therefore seems likely that only the vesicle-free and therefore very low viscosity lava from the lower parts of the proximal flows will be injected into the interiors of distal flows to cause inflation and contribute water to cause second boiling. Comparison of the three parts of Figure 4 shows that the larger the amount of water retained, the smaller the vertical extent of the part of the flow that contains it, until, for a large enough volatile content, there is no very low-viscosity, vesicle-free, water-retaining lower layer available for causing an injection of the kind postulated. 
Table 1 shows the consequences of the injection process for the range of values of residual dissolved volatile contents, $n_{\text {res }}$, in the lower parts of $4 \mathrm{~m}$ thick proximal lavas that can readily be injected into the $14 \mathrm{~m}$ thick distal part of the flow field (Figure 5). For this range of residual water contents, values are given for the depth, $D_{\mathrm{t}}$, to the top of the water-retaining lower layer, the thickness of the water-retaining layer, $D_{\mathrm{w}}$, and the thickness of the inflated distal lava flow after this injection. The intrusion process takes place after the eruption rate at the vent has become less than $\sim 3 \times 10^{4} \mathrm{~m}^{3} \mathrm{~s}^{-1}$, which Wilson and Head (2018b) show occurs after a time, $\tau$, of 10100 days. The distal flow will have been cooling during this period and will have developed thermal boundary layers at its upper and lower surfaces (Figure 5a), each having a thickness $\lambda$ of $\sim 2.3(\kappa \tau)^{1 / 2}$ (Turcotte and Schubert, 2002) where $\kappa$ is the thermal diffusivity of the lava, $\sim 10^{-6} \mathrm{~m}^{2} \mathrm{~s}^{-1}$, and using $\tau=20$ days, $\lambda=\sim 3 \mathrm{~m}$. Thus, only the central $(14-2 \times 3=) 8 \mathrm{~m}$ of the distal flow will still be at close to magmatic temperature and it is with this lava that the injected lava mixes. Column 4 of the table gives the result of adding the $14 \mathrm{~m}$ total thickness of the distal flow to the thickness of the injected proximal lava in column 3 to give the new thickness of the inflated flow, $D_{\mathrm{i}}$ (Figure $5 \mathrm{~b}$ ). Column 5 shows the result of sharing the residual volatile content $n_{\text {res }}$ of the injected lava with the $8 \mathrm{~m}$ thick flow core to produce a mean volatile content, $n_{\mathrm{m}}$, in the inflated core. Note that, due to the vertical structure of the proximal flows shown in Figure 4, the dissolved volatile content of the core after the injection is a maximum for a residual volatile content of $\sim 175 \mathrm{ppm}$, and is zero if $n_{\text {res }}$ is greater than $\sim 280 \mathrm{ppm}$.

\subsection{Flow cooling:}

Following cessation of eruptive activity at the vent, this mixture of old and new lava (Figure 5b) now continues to cool with no further significant horizontal movement. Waves of cooling continue to propagate into the lava from all of its boundaries. The great length and width of the flow relative to its thickness means that this can be treated as a one-dimensional problem with a planar cooling front propagating down from above and up from below. As crystallization induced by this cooling progresses, dissolved water is concentrated into the residual liquid, and this quickly becomes supersaturated so that second boiling takes place and gas bubbles nucleate in two expanding layers, one just below the upper cooling front and the other just above the lower cooling front (Figure 5c). We assume that the fraction of the residual water that is released is directly proportional to the degree of crystallization, i.e. to the volume fraction of crystals in the magma, $v_{\mathrm{c}}$, and that the process is efficient because of the presence of the crystals as nucleation sites. The water nucleates small $(\sim 10 \mu \mathrm{m})$ bubbles, the presence of which causes vertical expansion of the region they occupy to form a vesicular layer. The density of the water vapor and the bulk density and vesicle volume fraction at any point in the vesicular layer that is produced can be found from the local magma temperature, $T$, and pressure, $P$, the latter being the weight of the overlying flow material, i.e. the lithostatic pressure:

$$
P=g \rho D
$$

where $g$ is the acceleration due to gravity, $\rho$ is the density of the magmatic liquid, close to $3000 \mathrm{~kg} \mathrm{~m}^{-3}$ for all lunar basalts, and $D$ is the depth of the point being considered below the surface of the flow before any inflation has taken place. This is a good approximation to the pressure because, although gas release causing inflation 
increases the depth of a point below the surface, it does not, due to the small masses of gas involved, add significantly to the overlying total mass and hence weight and pressure. The local bulk density, $\beta$, of the vesicular lava is

$$
\beta=\left[((n Q T) /(m P)+(1-n) / \rho]^{-1}\right.
$$

where $n$ is the mass fraction of water released, $Q$ is the universal gas constant, 8.314 $\mathrm{kJ} \mathrm{kmol}^{-1} \mathrm{~K}^{-1}, T$ is taken as $1700 \mathrm{~K}$, and $m$ is the molecular weight of water, $18.02 \mathrm{~kg}$ $\mathrm{kmol}^{-1}$. The vesicularity, $v_{\mathrm{b}}$, i.e. the bubble volume fraction, of the lava is

$$
v_{\mathrm{b}}=n Q T \rho /[n Q T \rho+(1-n) m P]
$$

With an assumption about the specific composition of the basaltic liquid, the bulk viscosity of the vesicular lava, $\eta_{\mathrm{b}}$, can be evaluated from the temperaturedependent viscosity of the liquid alone, $\eta_{1}$, the fractional volume occupied by the crystals that have already formed, $v_{\mathrm{c}}$, and the fractional volume occupied by the gas bubbles, $v_{\mathrm{b}}$. A suitable formulation shown to be applicable to terrestrial basalts (Harris and Allen, 2008) when the gas bubbles are smaller than the crystals, as is likely to be the case here, is that of Phan-Thien and Pham (1997):

$$
\eta_{\mathrm{b}}=\eta_{1}\left\{1-\left[v_{\mathrm{b}} /\left(1-v_{\mathrm{c}}\right)\right]\right\}^{-5 / 2}\left(1-v_{\mathrm{c}}\right)^{-1}
$$

where a power law of the kind shown by Hulme (1973) to be suitable for lunar basalts, when fitted to the viscosity data for a low-Ti mare basalt analyzed by Williams et al. (2000), gives

$$
\eta_{1}=(1582.21 / T)^{11.5826}
$$

High-titanium basalts have a viscosity about a factor of two smaller (Williams et al., 2000). This slightly delays the change from turbulent to laminar flow mentioned in Section 3.

The remaining quantity required to solve the above equations is the temperature in the cooling flow, which varies with both depth and time. We are now dealing with a static flow that has developed a crust, the upper surface of which is maintained at a temperature very close to the lunar ambient by radiative exchange with its surroundings, and cooling is taking place by conduction to the surface and into the substrate (Figure 5c). We have approximated this process using an analytical model given by Carslaw and Jaeger (1959) for a layer of material of thickness $D_{\mathrm{i}}$ with an initial internal temperature $T_{\mathrm{i}}$ emplaced on a substrate at temperature $T_{\mathrm{s}}$ with the surface temperature abruptly set to $T_{\mathrm{s}}$ and maintained there. In our case $T_{\mathrm{i}}$ is the eruption temperature of the lava, taken to be the liquidus of the above low-Ti mare basalt, $1713 \mathrm{~K}, T_{\mathrm{s}}$ is the ambient lunar surface temperature assumed to average $200 \mathrm{~K}$ over the day-night cycle, and $D_{\mathrm{i}}$ is the thickness of the distal flow after injection of the proximal lava but before any second boiling, obtained from Table 1. Defining $\delta=T$ $T_{\mathrm{s}}$ and $\Delta=T_{\mathrm{i}}-T_{\mathrm{s}}$, the solution for the temperature $T$ as a function of depth $D$ and time $t$ is

$$
\delta=0.5 \Delta\left\{2 \operatorname{erf}[D / K]-\operatorname{erf}\left[\left(D-D_{\mathrm{i}}\right) / K\right]-\operatorname{erf}\left[\left(D+D_{\mathrm{i}}\right) / K\right]\right\}
$$


444

445

446

447

448

449

450

451

452

453

454

455

456

457

458

459

460

461

462

463

464

465

466

467

468

469

470

471

472

473

474

475

476

477

478

479

480

481

482

483

484

485

486

487

488

489

490

491

492

493 where $K=2(\kappa t)^{1 / 2}$. This treatment is an approximation for several reasons. It assumes that the substrate has the same thermal properties as the hot layer, but this is reasonable for new lava flows overlying older ones in the maria, especially as the thickness of regolith developed on earlier flows (at rates of $\sim 5 \mathrm{~mm} \mathrm{Ma}^{-1}$, Hörz et al., 1991) will generally be no more than a few percent of the thickness of a new flow. It ignores the thermal effects of latent heat release during crystallization and also ignores the fact that the presence of gas bubbles will modify the thermal diffusivity. The likely effect is that the model underestimates the time taken for the flow to reach a given configuration, but as we are more concerned with the physical consequences of vesiculation rather than the exact time at which they occur, this is acceptable.

We again adopt our nominal model of the basal part of a $4 \mathrm{~m}$ thick proximal flow providing lava to be injected into a $14 \mathrm{~m}$ thick distal flow (Figure 5a, 5b) and assume that the residual volatile content of the proximal lava is $100 \mathrm{ppm}$ water. Table 1 then shows that $3.42 \mathrm{~m}$ thickness of lava is injected, initially inflating the distal flow to a thickness of $17.42 \mathrm{~m}$ (Figure 5b). The mixing of the injected lava with the $8 \mathrm{~m}$ thick hot but volatile-free core of the distal flow reduces the effective water content of the molten lava to $30 \mathrm{ppm}$. The distal flow has already undergone enough cooling during the 20 days between its emplacement and the injection event to produce a $3 \mathrm{~m}$ layer of solid lava at its top and base. The subsequent development of the internal structure of the resulting combined flow body is now calculated as a function of time as further cooling takes place (Figure 5c-e). After each time increment, the amount of crystallization in the molten interior at a series of depths is calculated as a function of the local temperature, and the corresponding mass fraction of water exsolved is found. The local temperature and pressure are used to find the density of the gas, and the gas density and mass fraction together define the local bulk density of the lava. Finally, the volume fractions of crystals and gas bubbles determine the bulk liquid viscosity.

Figures $6 a-6 e$ show the variations of the key parameters with depth below the surface of the flow, (i) just before, (ii) just after, and at time intervals of (iii) 20, (iv) 30 and (v) 55 days after the injection event. The initially $14 \mathrm{~m}$ thick flow (Figure 5a) is inflated to a total thickness of $17.42 \mathrm{~m}$ by the injection of the as-yet unvesiculated but volatile-bearing lava (Figure 5b), and is then inflated to total thicknesses of 19.14, 24.56 (Figure 5c) and $33.76 \mathrm{~m}$ (Figure 5d) after 20, 30 and 55 days, respectively, due to the volume of foam generated by gas released as the injected lava cools. The successive parts of Figure 6 show, as a function of depth below the flow surface, $D$, the temperature, $T$, crystal volume fraction, $v_{\mathrm{c}}$, gas bubble volume fraction, $v_{\mathrm{b}}$, bulk density, $\beta$ and, where liquid is still present, the bulk viscosity, $\eta_{b}$, of the remaining crystal- and bubble-rich liquid lava. At both 20 and 30 days there is still a small region in the core of the flow where the temperature is still at the liquidus, but it is shrinking in extent. Both above and below this hot core, zones containing gas bubbles are present. The pressure due to the weight of the overlying material is less in the upper vesicular layer than in the lower layer, and so the vesicularity is greater in the upper layer than in the lower one (Figures 5c, 6). By 55 days all parts of the interior are below the liquidus and therefore contain some proportion of gas bubbles. The total vertical expansion of the flow due to the presence of the gas bubbles formed during the cooling process is (33.76-17.42=) $16.34 \mathrm{~m}$. Furthermore, despite the presence of the bubbles and crystals, the inherently low viscosity of lunar basalt means that almost all of this lava has a bulk viscosity less than $\sim 30 \mathrm{~Pa}$, with much of 
it less than $3 \mathrm{~Pa} \mathrm{~s}$, making it potentially very mobile. We adopt $\eta_{\mathrm{b}}=10 \mathrm{~Pa} \mathrm{~s}$ as a conservative representative value in the subsequent calculations.

\subsection{Subsequent flow evolution:}

Vesicularity (i.e. gas bubble volume fraction) profiles like those shown in Figures $6 \mathrm{c}$ and $6 \mathrm{~d}$ have been observed in many mafic lava flows on Earth at a variety of scales, from flows only a few meters thick at Surtsey (Sigmarsson et al., 2009) to flow units at least $20 \mathrm{~m}$ thick in the Columbia River flood basalt sequence (Hartley and Thordarson, 2009). Terrestrial flows with continuously vesicular regions in their centers appear to be very rare (but see Reidel, 2005, for a possible example), but this may be because gas bubbles have migrated out of the hottest central parts of these flows to be trapped in solidification fronts (Thordarson and Self, 1998; Hartley and Thordarson, 2009). Indeed, a common feature of all of these flows is the presence of segregation features, especially vesicle pipes, in which vesicle-rich liquid from the lower vesicular zone moves up through the core of the flow (Goff, 1996; Hartley and Thordarson, 2009). In some flows, unusually large "megavesicles" are seen at the bases of the upper vesicular zones (Sigmarsson et al., 2009). These comparisons strongly suggest that segregation structures will have formed in the lunar flows as gas bubbles migrate from the lower to the upper part of the flow core as shown in Figure 5e. The bulk density profile in Figure 6e shows that after 55 days the lava in the lower vesicular zone has attained its greatest buoyancy, thus encouraging its upward migration. Since the central core of the flow is the hottest part of the system and has the lowest bulk viscosity, it is entirely possible the rather than gas bubbles migrating out of the lower vesicular zone a Rayleigh-Taylor instability may drive the entire mass of foam upward. The centers of the upper and lower vesicular zones after 30 and 40 days are at depths of $\sim 4$ and $\sim 17 \mathrm{~m}$, where the pressures due to the overlying lava are $\sim 16$ and $80 \mathrm{kPa}$, respectively. If vesicular lava migrates from the lower to the upper zone (Figure 5e), the pressure it experiences will decrease by a factor of $(80 / 16$ $=) 5$ and the sizes of the gas bubbles it contains will have expanded by a factor of $\left(5^{1 / 3}\right.$ $=)$ 1.71. The significant differences between conditions in lava flows on the Moon and the Earth can be highlighted by noting that on Earth the pressures at the above 4 and $17 \mathrm{~m}$ depths in a flow would be 198.7 and $593.9 \mathrm{kPa}$, accounting for the greater value of $g$ and the Earth's atmospheric pressure of $100 \mathrm{kPa}$. The pressure reduction ratio would therefore be only $(\sim 593.9 / 198.7=) 2.989$ and the bubble expansion factor $\left(2.989^{1 / 3}=\right) 1.44$, significantly smaller than in the lunar case. The greater expansion of all bubbles added to the upper vesicular zone from the lower zone increases the inflation of the entire flow slightly but more importantly makes the vesicular lava in the upper zone even more buoyant than it was before. Combined with the low viscosity of the vesicular layer, these conditions strongly encourage escape of the vesicular lava through any fractures that form in the $\sim 3$ meter thick cooled crust of the flow (Figure 5e). We now explore the factors potentially influencing this process.

\subsection{Crack formation:}

The calculations above have been made for a uniformly thick distal flow assuming that the injection of proximal lava takes place everywhere within it, leading to uniform inflation. In practice, lava flows on the Moon are typically emplaced onto a previously emplaced lava flow with an irregularly impact-cratered surface. Rosenburg et al. (2011) describe a method of characterizing topographic roughness of planetary surfaces. The procedure uses digital altimetry data to calculate the RMS deviation of the slope as a function of the baseline length scale at which the slope is 
measured and to plot the logarithm of this quantity as a function of the logarithm of the baseline length. Most lunar highland surfaces produce a straight line on such a plot implying a single fractal law governing the change in roughness with scale, the consequence of impact cratering of the ancient anorthositic crust. However, the younger lunar mare surfaces have more complicated plots, characterized as bilinear or, most commonly, complex, with a distinct break in slope at a scale length in the range $\sim 200 \mathrm{~m}$ to $\sim 700 \mathrm{~m}$, indicating a change at this spatial wavelength from topography dominated by small-scale impact gardening to that controlled by the emplacement mechanisms of individual mare lava flows. We assume therefore that broad-scale variations in the thickness of new flows will occur mainly on these 200$700 \mathrm{~m}$ scales driven by the presence of earlier volcanically-controlled, rather than impact-controlled, topography. Inflation will be greater where flows are thicker, causing differential stresses and a non-random spatial distribution of fractures through which extrusions can take place. Furthermore, field experience of the patterns of inflation of compound pahoehoe flow systems on Earth shows that the interiors of the flows are clearly not laterally homogeneous, and that preferred, and meandering, pathways develop within them (Vye-Brown et al., 2013; Khalaf and Hammed, 2016; Rader et al., 2017). The same is likely to be true of inflating flows on the Moon.

The local slopes, $\alpha$, of lunar mare surfaces have been analyzed by Kreslavsky et al. (2013); these show that at length scales, $L$, of 200-700 m they are of order $10^{-2}$ to 6 $\times 10^{-3}$ (Kreslavsky, pers. comm., 2018). We have seen that inflation can double the total thickness of a flow. So, if two parts of a flow field are separated by the above typical length scales of $L=200-700 \mathrm{~m}$ and the above slopes exist between them, the flow in the lower elevation region is thicker than that in the shallower region by $\sim 2$ to $\sim 4$ meters, respectively. Initially both parts of the flow field can be assumed to have their surfaces at the same, equipotential, level. However, after inflation by a factor of 2 , the surface of the thicker part of the flow will have risen by an amount of 4 to 8 meters and will stand 2 to 4 meters above the originally shallower part of the flow. Thus, the cooled crust of the flow will have been flexed by this amount.

When flexing leads to fracture formation, fractures in the upper crust of a flow will likely have geometries similar to those of tumuli and similar features seen on the surfaces of inflating lava flows on Earth (Walker, 1991; Duraiswami et al., 2001; Duncan et al., 2004) and illustrated in the upper part of Figure 7. In one dimension the width, $W$, of a fracture can be estimated from the lower part of Figure 7 . The relationships are $c=0.5 L, 0.5 W=c-b, c^{2}=a^{2}+b^{2}$, and $a / c=\alpha$ which, since $\alpha$ is small, combine to give

$$
W=(L / 2) \alpha^{2}
$$

and so for $L$ in the range $200-700 \mathrm{~m}, W$ is in the range 10 to $13 \mathrm{~mm}$. These crack openings correspond to vertical uplift of the sides of the crack by 1 to $2 \mathrm{~m}$.

The opening of cracks is likely to begin as an episodic process. Slow cooling of the flow core produces steady inflation over a period of tens of days. At some point a crack forms in the lava crust. This exposes the top of the upper layer of vesicular lava foam to the external vacuum, and the bubbles in the top layer explode, allowing a mixture of released gas and chilling bubble wall glass shards to be ejected through the crack (Figure 8a). A wave of explosive decompression travels down into the foam 
layer (Jaupart and Vergniolle, 1989), and an acoustic wave also travels away from the crack into the foam as a result of the pressure reduction at the base of the crack. These waves will have similar speeds, of order tens of $\mathrm{m} \mathrm{s}^{-1}$ (Kieffer, 1977). The foam layer lava responds to the acoustic wave by accelerating toward the crack, but it is easy to show that the decompression wave will travel away from the crack very much faster than the vesicular magma can flow toward it. Disaggregated foam in the form of gas and liquid droplets (with sizes of $\sim 10-20 \mu \mathrm{m}$, the same order as the gas bubble size) will exit explosively through the crack leaving a potential space, so that the overlying crust is unsupported, and in extreme cases large-scale collapse of the crust into the space vacated by the entire foam layer could occur (Figure 8b). Largescale collapse may be linked to the formation of some types of the Irregular Mare Patches seen on mare surfaces (Braden et al., 2014; Qiao et al., 2017, 2018a, 2018b) but is not consistent with the morphologies of RMDSs.

We therefore infer that the RMDSs might form by a relatively slow inflation process, where small cracks form and discharge small amounts of disaggregated foam, and that this foam debris (some cooled bubble wall shards but mostly hot magma droplets) seals the cracks fast enough that sagging of the lava crust does not reach the stage of wholesale collapse. During this process, these cracking events produce a layer of debris over each crack site (Figure 8c), which we assume is confined to the highest part of the updomed crust as this is where stress is concentrated. Debris will collect extremely close to the cracks, because each jet of gas and entrained clasts will be heavily collimated by the crack sides, and as debris accumulates it will form an angle of rest cone. As the cone grows, the pressure at its base due to its weight increases, progressively reducing the violence of foam disaggregation when the crack is reactivated. When the cone gets sufficiently large, the pressure at its base will be equal to the pressure at the base of the lava crust, and so subsequent crack activation will not involve explosive activity (Figure 8c). Instead, foam will simply rise slowly through the crack and invade the base of the debris cone. We saw above that the pressure at the top of the foam under a $3 \mathrm{~m}$ thick flow crust was $\sim 14 \mathrm{kPa}$. If the expelled debris packs with $30 \%$ void space, the minimum cone height required to suppress explosive activity is $4.1 \mathrm{~m}$, and an angle of rest cone with this height has a basal diameter of $14.2 \mathrm{~m}$ and a volume of $219 \mathrm{~m}^{3}$ (Figure 8c). With the smallest scale length for mare surface topographic irregularities, $200 \mathrm{~m}$, the radius of a typical updomed region would be $c=\sim 100 \mathrm{~m}$ (see Figure 7), and so the volume of foam with vesicularity of $\sim 50 \%$ in a $3 \mathrm{~m}$ thick upper foam layer available to feed the intermittent explosive events would be ( $\pi \times$ $\left.100^{2} \times 3=\right) \sim 3.14 \times 10^{4} \mathrm{~m}^{3}$. Adjusting for the vesicularities of the foam and the debris mound, only $0.7 \%$ of the upper foam layer would need to be ejected to suppress explosive activity and start the process of inflation of the debris cone by injection of foam at its base. This difference in volume by two orders of magnitude suggests that the initial debris mound would be pushed aside and either buried or overridden by the subsequently extruded foam (Figure $5 \mathrm{e}$ ).

\subsection{Foam extrusion:}

This process of intermittent enlargement of the mound of extruded material on the flow surface would continue until there was some major change in the inflation rate of the lava flow itself. Such a change can be anticipated in the form of the generation of instabilities in the lower foam layer causing mini-diapirs feeding vesicle pipes to form and transport foam from the lower to the upper layer. We showed 
earlier that gas bubbles migrating from the lower to the upper zone would expand by a volume factor of $\sim 5$. Using Figure $6 \mathrm{~d}$, the lower vesicular zone extends between depths of 14 and $22 \mathrm{~m}$ and has an average vesicularity of $50 \%$. Thus a $4 \mathrm{~m}$ vertical extent consists of liquid lava and a $4 \mathrm{~m}$ vertical extent consists of gas. If half of this mixture is transferred to the lower pressure of the upper layer, the $2 \mathrm{~m}$ of gas in it expands to a $10 \mathrm{~m}$ vertical extent and the $2 \mathrm{~m}$ of liquid is unchanged, so the total vertical extent is $12 \mathrm{~m}$. However, this mixture came from a region with a vertical extent of $4 \mathrm{~m}$, so the net inflation, $I$, caused by the upward foam transfer is (12-4=) 8 meters. This is considerably greater than the 1 to $2 \mathrm{~m}$ uplift due to the uneven topography found above; using the equivalent geometry, it would lead to crack widths in the range 640 and $183 \mathrm{~mm}$ for $c=100$ and $350 \mathrm{~m}$, respectively, $\sim 50$ times greater than the earlier values.

Sudden uplift and production of a wide crack in the lava crust allows foam from the newly enriched upper foam layer to extrude into the existing debris mound and greatly enlarge it. The lava crust must subside at a speed that leads to a volume loss from the underlying foam layer that just balances the volume extrusion rate onto the surface. To model this process we assume the crack geometry shown in plan view in the upper left part of Figure 7, with two cracks crossing at right angles producing four crack segments. Other geometries would yield similar crack openings. Vesicular foams generally have a non-Newtonian rheology. Dollet and Raufast (2014, their Figure 5) provide data on the control of surface tension on foam rheology showing that a monodisperse foam should have a yield strength, $\tau_{\mathrm{y}}$, given by

$$
\tau_{\mathrm{y}}=K(\sigma / \phi)
$$

where $\sigma$ is the surface tension of the liquid-gas interface, $\sim 0.37 \mathrm{~J} \mathrm{~m}^{-2}$ for water in basalt (Mangan and Cashman, 1996) and $\phi$ is the typical bubble radius. The constant $K$ varies with the vesicularity of the foam, which Figure 6 shows is typically $\sim 50 \%$, for which $K$ is very close to $10^{-3}$ (Dollet and Raufast, 2014). Given that the bubbles in the injected lava flow will have nucleated with a radius of $\sim 10 \mu \mathrm{m}$, and that even those added to the upper layer from the lower layer will have expanded by less than a factor of 1.7 , we adopt $\phi=15 \mu \mathrm{m}$ so that $\tau_{\mathrm{y}}=\sim 25 \mathrm{~Pa}$. If a material with a yield strength rises through a parallel-sided channel, the flow consists of a zone of shearing fluid on either side of a central plug of width $Y$ given by

$$
Y=\left(2 \tau_{\mathrm{y}}\right) /\left[g\left(\rho_{\mathrm{o}}-\rho_{\mathrm{f}}\right)\right]
$$

where $\rho_{\mathrm{o}}$ is the density of the overburden and $\rho_{\mathrm{f}}$ is the density of the foam. The overburden at the crack site (Figure 8c) consists of about a $4 \mathrm{~m}$ thickness of loose debris with a porosity likely to be $\sim 30 \%$, implying a density of $2100 \mathrm{~kg} \mathrm{~m}^{-3}$, and a $3 \mathrm{~m}$ thickness of non-vesicular lava with density $3000 \mathrm{~kg} \mathrm{~m}^{-3}$, making the average overburden density close to $2500 \mathrm{~kg} \mathrm{~m}^{-3}$. The density of the $50 \%$ vesicular foam is $1500 \mathrm{~kg} \mathrm{~m}^{-3}$. With $\tau_{\mathrm{y}}=\sim 25 \mathrm{~Pa}$ this implies $Y=\sim 30 \mathrm{~mm}$. A foam with this yield strength cannot rise at all in a crack that is less than $30 \mathrm{~mm}$ wide. This $30 \mathrm{~mm}$ estimate is between $\sim 5$ and $16 \%$ of the 640 to $183 \mathrm{~mm}$ maximum crack widths derived above for $c=100$ and $350 \mathrm{~m}$, respectively. Using the upper part of Figure 7, this implies that the length, $X$, of the part of the crack through which foam can rise 
will be between 95 and $84 \%$ of the corresponding value of $c$, i.e., $X=95 \mathrm{~m}$ for $c=$ $100 \mathrm{~m}$ and $X=294 \mathrm{~m}$ for $c=350 \mathrm{~m}$.

As Figure 7 shows, the width of the crack decreases from $W$ at the widest point to $Y$ at the last point at which foam can rise through the crack. Let the local width of the crack be $w$ at a point distant $x$ from the last active point (Figure 7) and let $q$ be the ratio of the width of the central plug to the local width of the crack:

$$
q=Y / w
$$

In terms of this parameter, the speed, $U_{\text {plug }}$ of the central plug rising through the crack is given by Skelland (1967) as

$$
U_{\text {plug }}=\left[\left(1-q^{2}\right) w^{2} g\left(\rho_{\mathrm{o}}-\rho_{\mathrm{f}}\right)\right] /\left(8 \eta_{\mathrm{b}}\right)
$$

and the mean velocity of the foam, $U_{\mathrm{F}}$, including both sheared fluid and plug is

$$
U_{\mathrm{F}}=[(2+q) / 3] U_{\mathrm{plug}}
$$

The local volume flux of foam, $F_{1}$, escaping though each increment $\mathrm{d} x$ of the active crack is $\left(U_{\mathrm{F}} w \mathrm{~d} x\right)$ and the total flux in each half crack is found by integrating this numerically in a spreadsheet program using $\mathrm{d} x=0.1 X$. Table 2 shows how the various parameters vary with $x$ for both the $X=90 \mathrm{~m}$ and $245 \mathrm{~m}$ crack lengths, and for an intermediate case with $L=450 \mathrm{~m}, c=225 \mathrm{~m}, W=0.285 \mathrm{~m}$ and $X=200 \mathrm{~m}$. The total volume fluxes, $F_{\mathrm{t}}$, of foam released through a single crack are $\sim 109,21.7$ and 8.9 $\mathrm{m}^{3} \mathrm{~s}^{-1}$, respectively, and the totals from all four crack segments are $\sim 438,86.8$ and $35.6 \mathrm{~m}^{3} \mathrm{~s}^{-1}$, respectively. We now use these eruption rates to calculate the properties of the surface features that they produce.

The foam rising through the cracks intrudes into the base of the debris mound that has already accumulated and so there should be little change in its $\sim 50 \%$ vesicularity as long as it remains debris-covered. Where foam is erupted with no debris cover, which is most likely to occur at the narrow ends of the cracks, explosive decompression and debris formation will occur just as in the earlier phase of the activity until the foam is stabilized. The foam discharge rate is greatest at the widest part of each crack near the center of the uplifted area. The foam will spread both down-slope, approximately radially from the center of uplift, and also laterally away from the crack, at right-angles to the maximum slope, in the same way as any lava flow that exhibits a yield strength (Hulme, 1974). Let the flow that develops from a particular location on the crack where the volume flux being erupted is $F_{1}$ have levees each of width $W_{1}$ and maximum thickness $D_{1}$ and a central channel of width $W_{\mathrm{c}}$ and maximum thickness $D_{\text {c. }}$. Then Hulme (1974) showed that

$$
\begin{aligned}
& D_{\mathrm{l}}=\tau_{\mathrm{y}} /(\rho g \sin \alpha) \\
& W_{\mathrm{l}}=\tau_{\mathrm{y}} /\left(2 \rho g \sin ^{2} \alpha\right) \\
& D_{\mathrm{c}}=\left[\left(W_{\mathrm{t}} \tau_{\mathrm{y}}\right) /(\rho g)\right]^{1 / 2}
\end{aligned}
$$

where $W_{\mathrm{t}}$ is the total width of the flow, 


$$
W_{\mathrm{t}}=W_{\mathrm{c}}+2 W_{1}
$$

Wilson and Head (1983) found that the relationship between the central channel width $W_{\mathrm{c}}$ and the erupted volume flux $F_{1}$ could be simplified from Hulme's original more complex relationship using the good approximations

$$
\begin{array}{ll}
W_{\mathrm{c}}=\left[\left(24 F_{1} \eta_{\mathrm{p}}\right) /\left(\tau_{\mathrm{y}} \sin ^{2} \alpha\right)\right]^{1 / 3} & , W_{\mathrm{c}} /\left(2 W_{1}\right) \leq 1 \\
W_{\mathrm{c}}=\left[\left(24 F_{1} \eta_{\mathrm{p}}\right)^{4} \rho_{\mathrm{f}} g\right] /\left(\tau_{\mathrm{y}}^{5} \sin ^{6} \alpha\right)^{1 / 11} & , W_{\mathrm{c}} /\left(2 W_{1}\right) \geq 1
\end{array}
$$

The above system of equations has been solved for the three topographic scale lengths, $L=200,450$ and $700 \mathrm{~m}$, used earlier and for the estimated initial inflation, $I$, of $8 \mathrm{~m}$. The values are given for the total volume flux, $F_{\mathrm{t}}$, and so apply towards the lower end of the crack nearest to the original lava flow surface level. As foam is extruded onto the surface of the lava flow, the underlying structure of the flow must change. Our initial assumption was that the upraised surface slab of lava crust subsided back towards the horizontal as shown in Figure 9. However, as Figure 7 makes clear, this would necessarily reduce the width of each crack at every point along its length, making the escape of foam with a yield strength ever more difficult. To explore this, the above equations were also solved with $I=4 \mathrm{~m}$ and $2 \mathrm{~m}$ to track the subsidence of the crustal slabs. Table 3 shows the results. First, all of the foam flows are less than one meter thick. Second, although at the top of the upraised crustal slabs the embryonic flows from the four individual crack segments inevitably overlap and combine, in no case do they continue to do so as they descend the slope. Instead of forming a single mound they diverge into four separate flow lobes: this is shown by the fact that in all of the cases in Table 3 the total width of all four flows, ( 4 $\left.W_{\mathrm{t}}\right)$, is less than the circumference of the circular region occupied by the cracks, $(2 \pi$ $c)$, i.e., $W_{\mathrm{t}}<(\pi / 2) c$; the values of $[(\pi / 2) c]$ are given in the table for comparison with the values of $W_{\mathrm{t}}$. Finally, as $I$ decreases to less than $\sim 3 \mathrm{~m}$, the cracks become so narrow in the cases of $L=450$ and $700 \mathrm{~m}$ that foam can no longer be extruded. It is clear, therefore, that a response to foam extrusion in which the upraised crustal slabs simply rotate back towards the horizontal as in Figure 9 does not lead to significant extrusion of foam on the scale or with the geometry needed to explain the RMDSs.

An alternative response to foam extrusion is shown in Figure 10. In this scenario foam rises diapirically from the lower foam layer and supports the uptilted blocks of lava crust (Figure 10a) as they subside by a few meters nearly vertically, without rotating as they sink (Figure 10b). As they subside, foam extrudes through the cracks radiating from the center of the uplift which, because of the lack of crustal block rotation, now have a nearly constant width throughout the extrusion event (Figure 10c). The extrusion rate is greatest where the cracks are widest, and the foams from the four cracks immediately coalesce into a single body of fluid essentially emanating from a point source. There is now no progressive reduction in the extrusion rate, which remains essentially constant at its initial high value until the foam supply is exhausted. There is also no longer the bias against the formation of the larger mounds that was found with the previous geometry. The issue now becomes that of modelling the growth of a body of fluid having Bingham plastic rheology extruded from a point source. This problem was treated by Blake (1990), who found that the height $H$ of the resulting mound was related to its radius $R$ by 


$$
H=\left[\left(3.1 \tau_{\mathrm{y}} R\right) /(\rho g)\right]^{1 / 2}
$$

In our case the fluid density is that of the foam, $\rho_{\mathrm{f}}$, and presumably $R$ must be similar to our parameter $c$. We estimated $\tau_{\mathrm{y}}=25 \mathrm{~Pa}$ earlier, and so for $c$ in the range 100-225 $\mathrm{m}, H$ should lie in the range 1.8 to $2.7 \mathrm{~m}$. This height is measured above a presumed pre-existing flat surface in the case of Blake's (1990) model and so in our case it should logically be measured relative to the pre-existing surface level. Zhang et al. (2018a, b) have obtained the heights of 532 RMDSs, but their heights are measured relative to the base of the moat. Our model predicts (see Figure 10) that the depth of the moat produced by subsidence of the low end of the tilted crustal slab should be of the same order as the thickness of the upper foam layer, about $3 \mathrm{~m}$, and so our equivalents to the heights of Zhang et al. $(2018 \mathrm{a}, \mathrm{b})$ for $c$ in the range 100-225 m would be 4.8 to $5.7 \mathrm{~m}$. The average values found by Zhang et al. (2018a, b) for these dome heights are 3.5 to $6.0 \mathrm{~m}$. Given the considerable scatter in the measurements and the numerous assumptions in our model, we consider this to be entirely satisfactory agreement, supporting our proposal that the geometry of Figure 10 describes the system. Note that very little foam extrudes through the cracks in the crustal slabs underlying the moats because much of the foam originally in those regions will have migrated inward to feed the central uplift.

Table 2 shows the foam volume fluxes expected for single cracks in the 4-crack configuration of Figure 7. For $c=100$ and $225 \mathrm{~m}$ these are 109 and $21.7 \mathrm{~m}^{3} \mathrm{~s}^{-1}$, respectively. The corresponding total volume fluxes from all four cracks are therefore 436 and $87 \mathrm{~m}^{3} \mathrm{~s}^{-1}$. Zhang et al. (2018a, b) find that the typical volumes of RMDS mounds with radii 100 and $225 \mathrm{~m}$ are $\sim 30,000$ and $70,000 \mathrm{~m}^{3}$, respectively. This implies that the time intervals needed to emplace the mounds with these sizes are about 70 seconds in the first case and $\sim 13$ minutes in the second. These volume fluxes are the maxima that would apply with the cracks at their greatest extent. In practice a finite time is needed for a crack to expand to its greatest width, and the crack would begin to close after most of the foam was extruded. Even so, we see no reason to expect the time scales for mound formation to be more than a factor of two or three greater than the values given here.

\subsection{Implications of dome heights:}

Figure 2a shows that dome height tends to increase with dome diameter, but that the maximum dome height appears to be restricted to a value of $\sim 14 \mathrm{~m}$. In Figure 10 we have shown what we consider to be the most likely situation in which a large fraction of the locally-available foam is erupted onto the surface to form a mound, possibly with a contribution from foam migrating laterally from the surrounding flow to augment the local supply. If this is the case, then the height of the top of the mound above the bottom of its moat is an approximate indicator of the total vertical extent of foam in the flow before foam release onto the surface. For our nominal model shown in Figure 6, the total uplift of the flow due to gas release alone was $16.34 \mathrm{~m}$. The equivalent vertical uplifts for other values of the residual gas in the injected lava are shown in Figure 11. Recall that in Section 5.1 we showed in Table 1 the expected water mass fraction $n_{\mathrm{m}}$ in the core of the distal flow as a function of the water content in the magma leaving the lava pond at the vent, $n_{\text {res }}$ with $n_{\mathrm{m}}$ having a maximum when $n_{\text {res }}$ was $\sim 175$ ppm. This is now reflected exactly in Figure 11, with the uplift due to gas exsolution showing a maximum of $\sim 22 \mathrm{~m}$ when $n_{\text {res }}$ is $175 \mathrm{ppm}$. 
This leads to the striking implication that, at least for flows of the scale modeled here, no RMDS should have a height greater than $\sim 22 \mathrm{~m}$, probably somewhat less since it is unlikely that all of the available foam is extruded from a flow. This is clearly supported by the observed dome heights being restricted to less than $\sim 14 \mathrm{~m}$. Furthermore, the fact that domes with heights in the range 4-10 $\mathrm{m}$ are common implies that residual water contents in lavas leaving vent lava ponds were commonly in the range 25-250 ppm. Where foam extrusion occurs under other circumstances, for example from fractures in the crusts of lava lakes at the summits of small shield volcanoes, as at Ina (Qiao et al., 2017), conditions are likely to be different because more foam accumulation might occur. Even so, the mounds inferred to be foam extrusions on the floor of Ina typically have heights of 10-15 m with only a few approaching $20 \mathrm{~m}$ (Qiao et al., 2017).

\section{Summary and discussion:}

We have presented above a theoretical model for the formation and evolution of Ring Moat Dome Structures (RMDSs) that is based on the expected dynamics of lunar lava flows (Wilson and Head, 2018a; Head and Wilson, 2018) and is formulated to attempt to account for the major characteristics of these newly documented features (Zhang et al., 2017; 2018a,b). In this model, a mare basalt lava flow is emplaced from a fissure vent. In the early stages of the eruption, the flow leaving the vent contains extremely few dissolved volatiles and almost no exsolved gas bubbles due to the efficient loss of volatiles in pyroclastic hawaiian fire fountain activity at the vent. As it travels away from the vent area, the lava flow surface and base cool progressively, producing a distal flow with upper and lower solidified boundary layers and a molten core (Figure 5a). In the latter stage of the eruption at the vent, the magma rise speed decreases as the dike begins to close, and volatile bubbles can coalesce, favoring strombolian activity which removes much, but not all, of the volatiles from the magma. Magma containing 25-250 ppm of residual dissolved volatiles from this latter phase of the eruption is injected into the previously emplaced molten core of volatile-poor magma, causing flow inflation, substantially uplifting the surface of the flow (Figure 5b).

As the flow ceases to advance, crystallization of the lava causes supersaturation of residual dissolved volatiles in the injected core of the flow. The gas exsolved in this second boiling generates copious quantities of vesicles at the top and bottom of the central core of the flow, resulting in production of foam layers; additional flow inflation of many meters is predicted to accompany the formation of the foam layers Figures 5c, 5d). This additional inflation flexes the cooled upper crustal layer, and forms fractures that permit the buoyancy-driven extrusion of the magmatic foams onto the surface (Figure 5e). Magmatic foam extrudes through the cracks and forms circular mounds on the surface, i.e., the domes. Subsidence of the subjacent and surrounding surface, in response to the foam displacement, forms the ring moats around the mounds. The low viscosity of lunar basalts compared with terrestrial basalts, coupled with predicted high effusion rates in typical lunar eruptions and the absence of a lunar atmosphere, facilitates these processes in all flows with lengths greater than $\sim 50 \mathrm{~km}$ and thicknesses greater than $\sim 10 \mathrm{~m}$. Although second boiling and inflation are common features of many large basaltic flows on Earth, the formation of extremely vesicular foams, again the consequence of the low gravity and absence of atmosphere, is unique to the Moon and allows not only the upward flexing 
and fracture of lava flow surfaces but also the formation of the distinctive RMDS mounds by extrusion of the foam (Figures $5 \mathrm{e}, 10$ ).

The above model (see Figure 12 for a synthesis) has a number of implications that can be regarded as predictions to be tested using future morphological observations derived from high-resolution remote sensing and physical observations made in situ. The material forming the RMDS mounds is predicted to be a basaltic lava foam with $\sim 50-60 \%$ vesicularity overlain by a layer of shattered foam which is a mixture of glass shards and chilled droplets loosely packed with $\sim 30 \%$ void space. The mound formation process consists essentially of the redistribution of a given volume of vesicular lava from the interior of a lava flow onto its surface, and although there is clearly some change in the bulk density of this material as some of it explodes into the overlying vacuum, changing from coherent foam to a loose layer of fragments, the overall volume change should not be large, and so the volumes of each mound and its surrounding moat should be similar. Since the second boiling that leads to mound formation occurs within a stationary flow as it cools, the resulting RMDS is predicted to be un-deformed by shearing due to any lateral flow movement, as appears to be the case based on the first survey of RMDSs (Zhang et al., 2017). Extrusion of the foam from cracks radiating from the highest point of uplift of the underlying $\sim 3$ meter thick lava flow crust should generally lead to mounds with a near-circular shape because the morphology is controlled by the non-Newtonian rheology of the foam rather than by the underlying topography. However, the topography of flow surfaces can have height excursions of order meters at horizontal scales of tens of meters (Kreslavsky et al., 2017), for example due to a flow encountering impact craters on these scales during its emplacement, and in such cases extruded foam might collect in depressions or be diverted around high points, leading to more irregular RMDSs. Further sources of RMDS irregularity include (1) uneven surface topography due to multiple stages of flow inflation and lava crust bending, flexing and fracturing (Figures 5, 6); (2) the presence of crater-like depressions formed by foam collapse, gas venting and subsidence of cooled crust (Figure 8); and (3) sequential emplacement of RMDSs such that the formation of one feature scavengers foam from nearby parts of the flow and induces stresses that initiate a subsequent RMDS nearby. Predictable consequences of these processes include (1) somewhat linear chains of RMDS domes guided by fractures in distal flows due to pre-eruption topography or by pathways used by magma during late stage inflation and second boiling; and (2) asymmetric dome profiles due to preferential foam flow into depressions.

We have derived the results presented above in terms of a nominal mare basalt eruption scenario in which the distal parts of lava flow fields have thicknesses of $\sim 14$ $\mathrm{m}$ and the proximal parts thicknesses of $\sim 4 \mathrm{~m}$. Other patterns of variation of eruption rate with time are possible, though the trends of high to low discharge rate and consequent changes in morphology of the active part of the flow field seem inevitable (Wilson and Head, 2017a, 2018a). The penetration of cooling fronts into lava flows is controlled almost entirely by the thermal properties of the lava, such that the thicknesses of the cooled crusts at the top and base of a flow are similar functions of time until the two cooling fronts meet near the middle of the flow. Since this is the critical period for foam creation by second boiling, the time scale for the onset of RMDS formation, several tens of days after an eruption starts, is likely to be independent of the actual flow thickness as long as this is greater than about 10 
meters. Flows much thinner than this would probably not produce RMDSs at all because almost all of their interiors would have cooled well below the liquidus before conditions at the vent were suitable to cause late-stage lava injection into them. Thicker flows would be at least as likely to form RMDSs as those modeled here, and would probably be more likely to do so, and to produce mounds with greater heights, because increased flow thickness causes the pressure in the lower foam layer to be greater. As a result, the amount of expansion of the lower foam as it rises to join the upper foam layer is also greater, and the stress exerted on the overlying crust to form cracks is greater. The horizontal sizes of the RMDSs should not depend strongly on flow thickness, however, because we predict that these parameters are controlled mostly by horizontal irregularities in the topography onto which the flow is emplaced. Thus we would expect only a weak correlation between dome width and dome height, with considerable scatter in both parameters, as is observed (Zhang et al., 2018a, their Figure 1).

Our model (see Figure 12 for a synthesis) implies that, immediately after their formation (Figure 13a), RMDSs should consist of a highly fragmental layer overlying a foam layer in turn overlying a very low vesicularity lava flow crust, each layer being $\sim 2-3 \mathrm{~m}$ in thickness. This physical structure has implications for subsequent RMDS development under impact bombardment. The fragmental layer, consisting of the shattered walls of sub-mm sized bubbles, has very similar properties to those of mature mare regolith. Small-scale impacts into this material will simply re-distribute it on a sub-cm scale (Figure 13b). Somewhat larger impactors able to create a cavity more than 1-2 m deep and thus encounter the foam will produce anomalously shaped craters relative to the impactor size because of the efficient energy-absorbing aerogellike response of this very vesicular material (Durda et al., 2003; Kadono and Fujiwara, 2005; Qiao et al., 2017, 2018a, 2018b). Projectile kinetic energy partitioning into the foam layer favors crushing of foam vesicles rather than the brittle fracturing and ejection typical of impacts into coherent basalt bedrock. This may lead to unusual crater shapes. Such cratering events occurring at this early time are predicted to form pit craters on the dome/foam surfaces and normal craters on the adjacent surface of the solid upper flow layer. Impacts large enough to penetrate through the foam layer will encounter the uptilted bedrock slab, and produce flatbottomed craters with blocky floors and ejecta (Figure 13b). Impacts that occur on the boundary between the dome and the moat are predicted to have very unusual characteristics. The part of the crater forming on the rim and inner margin of the moat should be characterized by a substrate formed of the upper cooled solid basalt layer (see Figure 10), and should have a morphology similar to that of fresh blocky craters in basaltic substrates. The part of the crater forming on the dome itself will have a very different morphology, characterized by crushing of the foam substrate, probably a higher than usual depth-diameter ratio, few to no boulders, and enlargement of the rim by mass wasting of the crushed foam from the relatively steeper sides of the dome edge onto the crater floor. This type of configuration might be misinterpreted to mean that the mound foam flowed into the floor of a fresh crater, partially filling it. This would erroneously suggest a very young age for the foam emplacement event, significantly after the emplacement of the surrounding maria. Finally, after hundreds of millions to several billion years (Figure 13c), these initial dome substrate stratigraphic units (Figure 13a) will be largely obliterated and admixed by the development of an impact-generated regolith that could easily exceed the $\sim 4-6 \mathrm{~m}$ thickness of the initial layers (Figure 13a) overlying the solid basalt lava 
991 crust. In these latter stages, morphologies of craters superposed on domes should be

992 very similar to those of craters developed on adjacent, non-RMDS mare surfaces.

993 These evolutionary responses of superposed craters to regolith development may also

994 influence the impact crater size-frequency distributions, and thus inferred ages, of

995 RMDS features relative to non-RMDS maria. In situ examples of mature RMDS

996 regolith soils are predicted to have a much greater abundance of shattered walls of

997 sub-mm bubbles and fine foam fragments than typical non-RMDS regolith (Head and

998 Wilson, 2019).

Such a marked contrast in the physical properties of the dome and surrounding moat and flow materials may also help to account of the preservation of the topographically subtle moat for several billion years. Degradation of surface topography on mare flows is dominated by the processes of subsequent impact cratering and the resultant vertical gardening and lateral transport of ejecta to subdue adjacent topography. In this case, on the dome side of the moat, lateral transport is minimized in the earlier stages of regolith development due to the deep penetration of the projectile into the foam, and the dominance of substrate crushing rather than lateral transport and subduing of adjacent topography.

Our proposed model of lava flow injection, inflation, and second boiling is consistent with many of the observed characteristics of Ring Moat Dome Structures (RMDSs) as follows (Figure 12): 1) the generally circular shape and dome-like morphology interpreted as uplift and then subsidence accompanying foam extrusion. 2) The presence of a surrounding moat interpreted as subsidence of the outer rigid layer caused by foam evacuation from the subsurface. 3) The relatively large diameter/height ratio due to the low viscosity and low yield strength of the foam, consistent with expected foam properties. 4) The occurrence of RMDSs in clusters interpreted as inflation and second boiling taking place in a sheet-like rather than a channel-like configuration; occasional channel-like patterns might be manifested by more linear mounds. 5) The non-uniform distribution of RMDSs in mare regions because regions of volatile-rich flow inflation and foam extrusion are required, and these regions make up only a part of the total initial flow area, and are likely to occur preferentially in the proximal part of the flow field. 6) The similarity of RMDS mineralogy to that of the surrounding lava because both have the same source. 7) The common mound diameter range of $\sim 100-500 \mathrm{~m}$, consistent with the wavelength of surface undulations triggering foam migration in inflated flows. 8) The extreme rarity of overlapping mounds due to each mound potentially scavenging foam from the surrounding foam layer below the flexing lava crust. 9) The apparent young age of the domes due to the aerogel-like properties of the foams and the anomalously high depth-diameter ratio that this induces in impact craters. 10) The association of some RMDSs with irregular mare patches (IMPs) when both types of feature form close to the volcanic vent feeding the flows.

This model makes the following predictions that can be further tested with additional analyses of the characteristics and distribution of Ring Moat Dome Structures (RMDS) as follows:

1) RMDS will not form in typical mare flows unless the flows have been inflated by late-stage volatile-rich cores, and thus have undergone second boiling of volatile-rich lava; the presence of RMDSs will be a direct indicator of areas of flow inflation. 
2) Lava flows with thicknesses less than a few meters will not produce RMDSs due to the small volume of foam produced relative to the cooling boundary layer thickness, though the flows may undergo a small amount of inflation.

3) Initial fresh impact craters less than $\sim 30 \mathrm{~m}$ in diameter forming on RMDSs before extensive regolith has developed should have unusual characteristics (Figure 13b), lacking coarse ejecta (e.g., boulders) since they excavated only vesicular foam or low-strength fragmental debris. Following regolith development, differences in superposed crater morphology between RMDS domes and adjacent mare surfaces should be much less extreme (Figure 13c). Mature RMDS regolith soils are predicted to have a much greater abundance of shattered walls of sub-mm bubbles and fine foam fragments than typical non-RMDS regolith (Head and Wilson, 2019).

4) The presence of vesicular/low density material and the absence of coarse crater ejecta should cause RMDSs to give distinctive low-strength returns at RADAR wavelengths penetrating a few meters and should also produce thermal anomalies.

\section{Conclusions:}

We have utilized the newly documented characteristics of Ring Moat Dome Structures (RMDSs) (Zhang et al., 2017; 2018a, b) together with a theoretical model for the emplacement and cooling of mare basalts (Wilson and Head, 2017a; 2018, Head and Wilson, 2018) to develop a theoretical model accounting for RMDS characteristics (Figure 12). RMDSs are low mounds that occur in the lunar maria and appear to form synchronously with the surrounding mare basalt deposits. We interpret them to be due to inflation of the molten cores of cooling flows during the late stages of eruptions by injection of additional hot lava containing dissolved volatiles. Subsequent crystallization of this lava causes second boiling gas exsolution, generating copious quantities of vesicles at the top and bottom of the central core of the flow, forming magmatic foam layers that can accumulate into a single layer below the upper cooled crust of the flow. Flow inflation of many meters accompanies the formation of the foam layers, flexing the cooled upper crustal layer, and forming fractures. These cracks permit the buoyancy-driven extrusion of the magmatic foam onto the surface. Subsidence of the subjacent and surrounding surface occurs to form the moat. We have outlined several ways that this model can be tested by further observations of the morphology, morphometry and distribution of RMDSs. Finally, we leave as a subject for further work the detailed analysis of the morphological development of proximal lava flows with internal structures like those shown in Figure 4 when they are not injected into distal flow units. However, we suggest that there are foreseeable consequences of the cooling of such flows following their eruption. The examples in Figures 4(a) and (b), with total water contents up to 200 ppm, contain significant dissolved water that will be released during second boiling, causing extreme inflation as foam is formed. We suggest that subsequent large-scale collapse of the foam is a possible mechanism for the production of some of the Irregular Mare Patches (IMPs) documented by Braden et al. (2014) and by Qiao et al. (2017, 2018a, 2018b).

\section{Acknowledgements}

We are very grateful to Steve Self and two anonymous reviewers for their helpful suggestions for improving the clarity of this paper. LW thanks the Leverhulme Trust for support through an Emeritus Fellowship. FZ was supported by the Science and Technology Development Fund of Macau, Grant Nos. 131/2017/A3 and 119/2017/A3. We gratefully acknowledge funding to JWH for participation as co- 
1091 investigator in the LOLA Experiment Team (Grants NNX11AK29G and

1092 NNX13AO77G - National Aeronautics and Space Administration - Goddard). Much

1093 of the synthesis work for this contribution was enabled by participation in the NASA

1094 Solar System Exploration Research Virtual Institute, through the SEEED (SSERVI

1095 Evolution and Environment of Exploration Destinations) cooperative agreement

1096 number NNA14AB01A at Brown University. Thanks are extended to Anne Côté for 1097 help in figure drafting and manuscript preparation.

1098 
1099 Table 1. Parameters relating to the injection of lava erupted late in an eruption into

1100 the core of a $14 \mathrm{~m}$ thick stagnant lava flow emplaced in the early stages of the same

1101 eruption. The early stage lava lost most of its volatiles in a fire fountain at the vent

1102 and is very vesicle-poor. The late stage lava is $4 \mathrm{~m}$ thick and consists of three layers:

1103 a fragmental upper layer overlies a very vesicular layer which in turn overlies a

1104 vesicle-free basal layer still containing a mass fraction $n_{\text {res }}$ in ppm of volatiles

1105 dominated by $\mathrm{H}_{2} \mathrm{O}$. The top of the basal layer is at a depth $D_{\mathrm{t}}$ below the top surface of 1106 the $4 \mathrm{~m}$ layer and the basal layer has a thickness $D_{\mathrm{w}}$. Injection of this volatile-bearing

1107 lava into the core of the $14 \mathrm{~m}$ thick distal flow inflates the distal flow to a new total

1108 thickness $D_{\mathrm{i}}$. After mixing between the injected lava and the original core lava, the

1109 core has a dissolved water content of $n_{\mathrm{m}}$, available to be released as gas bubbles when

1110 cooling and crystallization causes second boiling to occur.

1111

1112

1113

$n_{\text {res }}$

$D_{\mathrm{t}}$

0.02

$D_{\mathrm{w}}$

$D_{\text {i }}$

17.98

$n_{\mathrm{m}}$

1114

0.06

3.98

17.94

3.3

1115

25

0.18

3.94

17.82

8.2

1116

0.35

3.82

17.65

16.1

1117

75

0.58

3.65

17.42

23.5

1118

0.87

3.42

17.13

30.0

1119

1.22

3.13

16.78

35.2

1120

1.64

2.78

16.36

38.7

1121

2.12

2.36

39.9

1122

200

2.67

1.88

15.88

38.1

1123

3.28

1.33

15.33

32.1

1124

250

0.72

14.72

20.6

3.96

0.04

14.04

1.4

1125

1126 
1127

1128

1129

1130

1131

1132

1133

1134

1135

1136

1137

1138

1139

1140

1141

1142

1143

1144

1145

1146

1147

1148

1149

1150

1151

1152

1153

1154

1155

1156

1157

1158

1159

1160

1161

1162

1163

1164

1165

1166

1167

1168

1169

1170

1171

1172

1173

1174

1175

1176

Table 2. Parameters of foam extrusion through the cracks in the lava crust to form surface foam flows for three horizontal scales of features. Values given as a function of distance along active part of crack, $x$, in meters are: local crack width, $w$, in meters; ratio of plug width to crack width, $q$; mean speed of foam in crack, $U_{\mathrm{F}}$, in $\mathrm{m} \mathrm{s}^{-1}$;

Reynolds number, $R e$, of fluid in crack; and local volume flux of foam, $F_{1}$, in $\mathrm{m}^{3} \mathrm{~s}^{-1}$.

The total volume flux from the crack is given at the bottom of the last column.

(a) Crack with $c=100 \mathrm{~m}, X=95.2 \mathrm{~m}, W=0.64 \mathrm{~m}$

\begin{tabular}{rlrrrr}
$x$ & $w$ & $q$ & $U_{\mathrm{F}}$ & \multicolumn{1}{c}{$R e$} & \multicolumn{1}{c}{$F_{1}$} \\
9.52 & 0.09 & 0.34 & 0.12 & 1.6 & 0.10 \\
19.04 & 0.15 & 0.20 & 0.33 & 7.6 & 0.49 \\
28.56 & 0.21 & 0.14 & 0.65 & 20.8 & 1.32 \\
38.07 & 0.27 & 0.11 & 1.06 & 43.9 & 2.78 \\
47.59 & 0.34 & 0.09 & 1.58 & 79.6 & 5.05 \\
57.11 & 0.40 & 0.08 & 2.20 & 130.8 & 8.30 \\
66.63 & 0.46 & 0.07 & 2.91 & 200.2 & 12.70 \\
76.15 & 0.52 & 0.06 & 3.73 & 290.5 & 18.43 \\
85.67 & 0.58 & 0.05 & 4.65 & 404.5 & 25.67 \\
95.19 & 0.64 & 0.05 & 5.67 & 545.0 & $\underline{34.58}$ \\
& & & & & 109.43
\end{tabular}

(b) Crack with $c=225 \mathrm{~m}, X=200.6 \mathrm{~m}, W=0.284 \mathrm{~m}$

\begin{tabular}{cccccc}
$x$ & $w$ & $q$ & $U_{\mathrm{F}}$ & \multicolumn{1}{l}{$R e$} & $F_{1}$ \\
20.06 & 0.06 & 0.55 & 0.04 & 0.32 & 0.04 \\
40.12 & 0.08 & 0.38 & 0.09 & 1.12 & 0.15 \\
60.18 & 0.11 & 0.29 & 0.16 & 2.60 & 0.35 \\
80.24 & 0.13 & 0.23 & 0.25 & 4.95 & 0.66 \\
100.30 & 0.16 & 0.20 & 0.35 & 8.38 & 1.12 \\
120.36 & 0.18 & 0.17 & 0.48 & 13.09 & 1.75 \\
140.42 & 0.21 & 0.15 & 0.62 & 19.26 & 2.58 \\
160.47 & 0.23 & 0.13 & 0.77 & 27.11 & 3.63 \\
180.53 & 0.26 & 0.12 & 0.95 & 36.82 & 4.92 \\
200.59 & 0.28 & 0.11 & 1.14 & 48.60 & $\underline{6.50}$ \\
& & & & & 21.70
\end{tabular}

(c) Crack with $c=350 \mathrm{~m}, X=290.9 \mathrm{~m}, W=0.183 \mathrm{~m}$

$\begin{array}{cccccl}x & w & q & U_{\mathrm{F}} & R e & F_{1} \\ 29.09 & 0.05 & 0.67 & 0.02 & 0.1 & 0.03 \\ 58.19 & 0.06 & 0.50 & 0.05 & 0.4 & 0.08 \\ 87.28 & 0.08 & 0.40 & 0.08 & 0.9 & 0.18 \\ 116.37 & 0.09 & 0.34 & 0.12 & 1.6 & 0.31 \\ 145.47 & 0.11 & 0.29 & 0.16 & 2.6 & 0.50 \\ 174.56 & 0.12 & 0.25 & 0.21 & 3.9 & 0.75 \\ 203.65 & 0.14 & 0.22 & 0.27 & 5.5 & 1.07 \\ 232.75 & 0.15 & 0.20 & 0.33 & 7.6 & 1.47 \\ 261.84 & 0.17 & 0.18 & 0.40 & 10.1 & 1.95 \\ 290.93 & 0.18 & 0.17 & 0.48 & 13.0 & \underline{2.53} \\ & & & & & 8.89\end{array}$


1177 Table 3. Parameters of foam extrusion through cracks in the lava crust to form

1178

1179

1180

1181

1182

1183

1184

1185

1186

1187

1188

1189

1190

1191

1192

1193

1194

1195

1196

1197

1198

1199

1200

1201

1202

1203

1204 surface foam flows for three horizontal scales of features. As the inflation $I$ of the lava surface decreases, values are given for the maximum thickness $D_{\mathrm{b}}$ and width $W_{\mathrm{b}}$ of the levee on each side of the flow, the width $W_{\mathrm{c}}$ of the central channel, the total flow width $W_{\mathrm{t}}$, and the center-line thickness of the flow $D_{\text {c. }}$ Values of $[(\pi / 2) c]$ are given for comparison with values of $W_{\mathrm{t}}$. All values are in meters.

Crack with $L=200 \mathrm{~m}, c=100 \mathrm{~m}, X=95.2 \mathrm{~m},(\pi / 2) c=157 \mathrm{~m}$

$\begin{array}{rrrrrr}I & D_{\mathrm{b}} & W_{\mathrm{b}} & W_{\mathrm{c}} & W_{\mathrm{t}} & D_{\mathrm{c}} \\ 8 & 0.13 & 0.8 & 75.5 & 77.1 & 0.89 \\ 4 & 0.26 & 3.2 & 24.2 & 30.6 & 0.56 \\ 2 & 0.51 & 12.9 & 5.1 & 30.8 & 0.56\end{array}$

Crack with $L=450 \mathrm{~m}, c=225 \mathrm{~m}, X=200.6 \mathrm{~m},(\pi / 2) c=353 \mathrm{~m}$

$\begin{array}{rrrrrr}I & D_{\mathrm{b}} & W_{\mathrm{b}} & W_{\mathrm{c}} & W_{\mathrm{t}} & D_{\mathrm{c}} \\ 8 & 0.29 & 4.1 & 65.2 & 73.3 & 0.87 \\ 4 & 0.58 & 16.3 & 19.9 & 52.4 & 0.73\end{array}$

Crack with $L=700 \mathrm{~m}, c=350 \mathrm{~m}, X=290.9 \mathrm{~m},(\pi / 2) c=550 \mathrm{~m}$

$\begin{array}{rrrrrr}I & D_{\mathrm{b}} & W_{\mathrm{b}} & W_{\mathrm{c}} & W_{\mathrm{t}} & D_{\mathrm{c}} \\ 8 & 0.45 & 9.8 & 60.0 & 79.7 & 0.91 \\ 4 & 0.90 & 39.4 & 15.6 & 94.3 & 0.99\end{array}$




\section{Notation}

$1207 \quad D \quad$ depth below surface of lava flow

$1208 D_{1} \quad$ thickness of lava in central channel of foam flow

$1209 \quad D_{\text {d }} \quad$ flow thickness in distal part of lava flow

$1210 \quad D_{\mathrm{f}} \quad$ initial thickness of lava flow

$1211 \quad D_{\mathrm{i}} \quad$ distal flow thickness between proximal lava injection and second boiling

$1212 \quad D_{1} \quad$ thickness of levee of foam flow

$1213 D_{\mathrm{p}} \quad$ flow thickness in proximal part of lava flow

$1214 D_{\mathrm{t}} \quad$ depth to top of part of flow still containing dissolved water

$1215 D_{\mathrm{w}} \quad$ thickness of layer of lava still containing dissolved water

$1216 E$ maximum uplift of lava flow surface due to foam concentration

$1217 \quad F \quad$ dense rock equivalent lava volume eruption rate from vent

$1218 \quad F_{1} \quad$ local volume flux of foam from an increment of crack length

$1219 F_{\mathrm{t}} \quad$ total volume flux of foam from one crack

$1220 \quad G \quad$ acceleration due to gravity

$1221 \quad H \quad$ height of dome constructed from Bingham plastic fluid

$1222 \quad I \quad$ amount of vertical flow inflation

$1223 \quad K \quad$ the parameter $2(\kappa t)^{1 / 2}$

$1224 L \quad$ separation of two locations on flow

$1225 \quad P \quad$ pressure within lava flow

$1226 \quad P_{\mathrm{b}} \quad$ pressure in gas bubble

$1227 \quad Q \quad$ universal gas constant

$1228 R \quad$ radius of dome constructed from Bingham plastic fluid

$1229 \quad R e \quad$ Reynolds number of flowing fluid

$1230 \quad T \quad$ temperature within lava flow

$1231 T_{\mathrm{i}} \quad$ eruption temperature of lava

$1232 T_{\mathrm{s}}$ average ambient lunar surface temperature

$1233 U_{\mathrm{f}} \quad$ mean speed of lava flow

$1234 U_{\mathrm{d}} \quad$ rise speed of the magma rising through the dike

$1235 U_{\text {plug }}$ speed of unsheared plug in flow of Bingham plastic

$1236 U_{\mathrm{F}} \quad$ mean speed of flowing Bingham plastic lava foam

$1237 \quad W \quad$ width of fracture in lava crust

$1238 W_{\mathrm{f}} \quad$ lava flow width

$1239 W_{1} \quad$ width of levee on foam flow

$1240 \quad W_{1} \quad$ width of central channel of foam

$1241 W_{\mathrm{t}} \quad$ total width of foam flow

$1242 X \quad$ length of crack within which lava is moving

$1243 \quad Y \quad$ width of central plug in lava in crack

$1244 a$ uplift of lava surface

$1245 \quad b \quad$ projection of $c$ onto horizontal plane

$1246 \quad c \quad$ length of uplifted lava slab

$1247 f \quad$ wall friction factor for turbulent fluid flow

$1248 \mathrm{~m}$ molecular weight of water

$1249 n$ mass fraction of water released from lava

$1250 \quad n_{\text {res }} \quad$ water content of lava in proximal flow

$1251 q$ ratio of plug width to local crack with

$1252 t$ time since start of cooling

$1253 v_{\mathrm{b}} \quad$ bubble volume fraction in lava

$1254 v_{\mathrm{c}} \quad$ volume fraction of crystals in magma 
$1255 \quad w \quad$ local width of crack in lava crust

$1256 x$ distance along crack

$1257 \Delta \quad$ temperature difference $\left(T_{\mathrm{i}}-T_{\mathrm{s}}\right)$

$1258 \alpha \quad$ local slope of mare surface

$1259 \quad \beta \quad$ bulk density of vesicular lava

$1260 \delta \quad$ temperature difference $\left(T-T_{\mathrm{s}}\right)$

$1261 \eta_{\mathrm{b}} \quad$ bulk viscosity of vesicular lava

$1262 \quad \eta_{1} \quad$ viscosity of magmatic liquid

$1263 \kappa \quad$ thermal diffusivity of lava

$1264 \lambda \quad$ cooled boundary layer thickness at both top and base of a lava flow

$1265 \phi \quad$ gas bubble diameter

$1266 \rho$ density of magmatic liquid

$1267 \rho_{\text {o }}$ density of overburden at crack site

$1268 \rho_{\mathrm{f}} \quad$ density of magmatic foam

$1269 \sigma \quad$ surface tension of gas-liquid interface

$1270 \tau \quad$ time since lava left vent

$1271 \tau_{\mathrm{y}} \quad$ yield strength of magmatic foam

1272

1273 
1274

1275

1276

1277

1278

1279

1280

1281

1282

1283

1284

1285

1286

1287

1288

1289

1290

1291

1292

1293

1294

1295

1296

1297

1298

1299

1300

1301

1302

1303

1304

1305

1306

1307

1308

1309

1310

1311

1312

1313

1314

1315

1316

1317

1318

1319

1320

1321

1322
References

Aubele, J.C., Crumpler, L.S., Elston, W. E., 1988. Vesicle zonation and vertical structure of basalt flows. J. Volcanol. Geotherm. Res. 35, 349-374.

Beresford, S., Cas, R., Lahaye, Y., Jane, M., 2002. Facies architecture of an Archean komatiite-hosted Ni-sulphide ore deposit, Victor, Kambalda, Western Australia: implications for komatiite lava emplacement. J. Volcanol. Geotherm. Res. 118(1-2), 57-75.

Blackburn, E.A., Wilson, L., Sparks, R.S.J., 1976. Mechanisms and dynamics of strombolian activity. J. Geol. Soc. Lond. 132(4), 429-440.

Blake, S., 1990. Viscoplastic models of lava domes. In Lava flows and domes: emplacement mechanisms and hazard implications, J. Fink, ed., IAVCEI Proceedings in Volcanology 2, 88-128, Springer-Verlag, New York.

Braden, S.E., Stopar, J.D., Robinson, M.S., Lawrence, S.J., van der Bogert, C.H., Hiesinger, H., 2014. Evidence for basaltic volcanism on the Moon within the past 100 million years. Nature Geosci. 7 (11), 787-791, doi:10.1038/NGEO2252

Carslaw, H.S., Jaeger, J. C., 1959. Conduction of Heat in Solids. Clarendon Press, Oxford.

Dollet, B., Raufaste, C., 2014. Rheology of aqueous foams. Comptes Rendus de l'Academie des Sciences Serie IV 15(8-9), 731-747, doi:10.1016/j.crhy.2014.09.008

Duncan, A.M., Guest, J.E., Stofan, E.R. Anderson, S.W., Pinkerton, H., Calvari, S., 2004. Development of tumuli in the medial portion of the 1983 aa flow-field, Mount Etna, Sicily. J. Volcanol. Geotherm. Res. 132, 173-187, doi:10.1016/S03770273(03)00344-5

Duraiswami, R.A., Bondre, N.R., Dole, G., Phadnis, V.M., Kale, V.S., 2001. Tumuli and associated features from the western Deccan Volcanic Province, India. Bull. Volcanol. 63(7), 435-442, doi:10.1007/s004450100160

Durda, D.D., Flynn, G.J., Van Veghten, T.W., 2003. Impacts into porous foam targets: possible implications for the disruption of comet nuclei. Icarus 163, 504-507, doi:10.1016/S0019-1035(03)00070-8

Elder, C.M., Hayne, P.O., Bandfield, J.L., Ghent, R.R., Williams, J.P., Hanna, K.L.D., Paige, D.A., 2017. Young lunar volcanic features: Thermophysical properties and formation. Icarus 290, 224-237, doi:10.1016/j.icarus.2017.03.004

Fielder, G., Guest, J.E., Wilson, L., Rogers, P.S., 1967. New data on simulated lunar material. Planet. Space Sci. 15(11), 1653-1666.

Garry, W.B., Robinson, M.S., Zimbelman, J.R., Bleacher, J.E., Hawke, B.R., Crumpler, L.S., Braden, S.E., Sato, H., 2012. The origin of Ina: Evidence for 
inflated lava flows on the Moon. J. Geophys. Res.-Planets 117, E00H31, doi:10.1029/2011JE003981

Goff, F., 1996. Vesicle cylinders in vapor-differentiated basalt flows. J. Volcanol. Geotherm. Res. 71, 167-185.

Grove, T.L., Krawczynski, M.J., 2009. Lunar mare volcanism: where did the magmas come from? Elements 5, 29-34.

Harris, A.J.L., Allen, J.S., 2008. One-, two- and three-phase viscosity treatments for basaltic lava flows. J. Geophys. Res. 113, B09212, 15 pp., doi:10.1029/2007JB005035

Hartley, M.E., Thordarson, T. (2009) Melt segregations in a Columbia River Basalt lava flow: A possible mechanism for the formation of highly evolved mafic magmas. Lithos 112, 434-446.

Head, J.W., 1976. Lunar volcanism in space and time. Rev. Geophys. Space Phys. 14, 265-300.

Head, J.W., Wilson, L., 1992. Lunar mare volcanism: stratigraphy, eruption conditions, and the evolution of secondary crusts. Geochim. Cosmochim. Acta 56(6), 2155-2175.

Head, J.W., Wilson, L., 2017. Generation, ascent and eruption of magma on the Moon: new insights into source depths, magma supply, intrusions and effusive/explosive eruptions (Part 2: Observations). Icarus 283, 176-223, doi:10.1016/j.icarus.2016.05.031

Head, J.W., Wilson, L., 2018. Lunar basaltic volcanic eruptions: gas release patterns and variations in lava vesicularity: fissures, mare flows, and ring-moat dome structure (RMDS) morphology. Ninth Moscow Solar System Symposium, 9MS3MN-06.

Head, J.W., Wilson, L., 2019. Rethinking lunar mare basalt regolith formation: new concepts of lava flow protolith and evolution of regolith thickness and internal structure. Lunar and Planetary Science L, abstract \#2532.

Hess, P.C., 2000. On the source region for mare picrite glasses. J. Geophys. Res. 105(E2), 4347-4360.

Hiesinger, H., Head, J.W., 2006. New views of lunar geoscience: An introduction and overview, In: Jolliff, B., Wiezcorek, M., (Eds), New Views of the Moon, Rev. Mineral. Geochem. 60, 1-81.

Hon, K., Kauahikaua, J., Denlinger, R., Mackay, K., 1994. Emplacement and inflation of pahoehoe sheet flows: observations and measurements of active lava flows on Kilauea Volcano, Hawaii. Geol. Soc.Amer. Bull. 106(3), 351-370, doi:10.1130/0016-7606(1994)106<0351:EAIOPS>2.3.CO;2 
Hörz, F., Grieve, R., Heiken, G., Spudis, P., Binder, A., 1991. Lunar surface processes, pp. 61-120 in The Lunar Source Book, eds. Heiken, G. H. et al., Cambridge Univ. press.

Hulme, G., 1973. Turbulent lava flow and the formation of lunar sinuous rilles, Mod. Geol. 4, 107-117.

Hulme, G., 1974. The interpretation of lava flow morphology. Geophys. J. Roy. Astron. Soc. 39, 361-383.

Jaupart, C., Vergniolle, S., 1989. The generation and collapse of a foam layer at the roof of a basaltic magma chamber. J. Fluid Mech. 203, 347-380.

Kadono, T., Fujiwara, A., 2005. Cavity and crater depth in hypervelocity impact. Internat. J. Impact Eng. 3, 1309-1317, doi:10.1016/j.ijimpeng.2004.08.003

Khalaf, E.E.D.A.H., Hammed, M.S., 2016. Morphology and development of pahoehoe flow-lobe tumuli and associated features from a monogenetic basaltic volcanic field, Bahariya Depression, Western Desert, Egypt. J. African Earth Sci. 113, 165180.

Kieffer, S.W., 1977. Sound speed in liquid-gas mixtures: water-air and water-steam. J. Geophys. Res. 82, 895-904.

Kolzenburg, S., Jaenicke, J., Muenzer, U., Dingwell, D.B., 2018. The effect of inflation on the morphology-derived rheological parameters of lava flows and its implications for interpreting remote sensing data - A case study on the 2014/2015 eruption at Holuhraun, Iceland. J. Volcanol. Geotherm. Res. 357, 200-212, doi:10.1016/j.jvolgeores.2018.04.024

Kreslavsky, M.A., Head, J.W., Neumann, G.A., Rosenburg, M.A., Aharonson, O., Smith, D.E., Zuber, M.T., 2013. Lunar topographic roughness maps from Lunar Orbiter Laser Altimeter (LOLA) data: Scale dependence and correlation with geologic features and units. Icarus 226, 52-66.

Kreslavsky, M.A., Head, J.W., Neumann, G.A., Zuber, M.T., Smith, D.E., 2017. Lowamplitude topographic features and textures on the Moon: initial results from detrended Lunar Orbiter Laser Altimeter (LOLA) topography. Icarus 283, 138-145, doi:10.1016/j.icarus.2016.07.017

Llewellin, E.W., Del Bello, E., Taddeucchi, J., Scarlato, P., Lane, S.J., 2012. The thickness of the falling film of liquid around a Taylor bubble. Proc. Roy. Soc. A468 (2140), 1041-1064, doi:10.1098/rspa.2011.0476

Mangan, M.T., Cashman, K.V., 1996. The structure of basaltic scoria and reticulite and inferences for vesiculation, foam formation, and fragmentation in lava fountains. J. Volcanol. Geotherm. Res. 73, 1-18.

Morey, G.W., 1922. The development of pressure in magmas as a result of crystallization. J. Washington Acad. Sci. 12(9), 219-230. 
1423

1424

1425

1426

1427

1428

1429

1430

1431

1432

1433

1434

1435

1436

1437

1438

1439

1440

1441

1442

1443

1444

1445

1446

1447

1448

1449

1450

1451

1452

1453

1454

1455

1456

1457

1458

1459

1460

1461

1462

1463

1464

1465

1466

1467

1468

1469

1470
Murase, T., McBirney, A.R., 1970. Viscosity of lunar lavas. Science, 167(3924), 1491-1493, doi:10.1126/science.167.3924.1491

Pering, T.D., McGonigle, A.J.S., 2018. Combining spherical-cap and Taylor bubble fluid dynamics with plume measurements to characterize basaltic degassing. Geosciences 8, 42, 14 pp., doi:10.3390/geosciences8020042

Phan-Thien, N., Pham, D.C., 1997. Differential multiphase models for polydisperse suspensions and particulate solids. J. Non-Newtonian Fluid Mech. 72, 305-318.

Pinkerton, H., Wilson, L., 1994. Factors controlling the lengths of channel-fed lava flows. Bull. Volcanol. 56(2), 108-120.

Qiao, L., Head, J.W., Wilson, L., Xiao, L., Kreslavsky, M., Dufek, J., 2017.) Ina pit crater on the Moon: extrusion of waning-stage lava lake magmatic foam results in extremely young crater retention ages. Geology 45(5), 455-458, doi:10.1130/G38594.1

Qiao, L., Head, J.W., Xiao, L., Wilson, L., Dufek, J.D., 2018a. The role of substrate characteristics in producing anomalously young crater retention ages in volcanic deposits on the Moon: Morphology, topography, sub-resolution roughness and mode of emplacement of the Sosigenes Lunar Irregular Mare Patch (IMP). Meteorit. Planet. Sci. 53(4), 778-812, doi:10.1111/maps.13003

Qiao, L., Head, J.W., Wilson, L., Ling, Z., 2018b. Lunar Irregular Mare Patch subtypes: linking their origin through hybrid relationships displayed at Cauchy 5 small shield volcano. Lunar and Planetary Science XLIX, abstract \#1390.

Rader, E. Vanderkluysen, L., Clarke, A., 2017. The role of unsteady effusion rates on inflation in long-lived lava flow fields. Earth Planet. Sci. Lett. 477, 73-83.

Reidel, S.P., 2005. A lava flow without a source: the Cohassett flow and its compositional components, Sentinal Bluffs Member, Columbia River Basalt group. J. Geol. 113, 1-21, doi:10.1086/425966

Robinson, M.S., Brylow, S.M., Tschimmel, M., Humm, D., Lawrence, S.J., Thomas, P.C., Denevi, B.W., Bowman-Cisneros, E., Zerr, J., Ravine, M.A., Caplinger, M.A., Ghaemi, F.T., Schaffner, J.A., Malin, M.C., Mahanti, P., Bartels, A., Anderson, J., Tran, T.N., Eliason, E.M., McEwen, A.S., Turtle, E., Jolliff, B.L., Hiesinger, H., 2010. Lunar Reconnaissance Orbiter Camera (LROC) instrument overview. Space Sci .Rev. 150, 81-124, doi: 10.1007/s11214-010-9634-2

Rosenburg, M.A., Aharonson, O., Head, J.W., Kreslavsky, M.A., Mazarico, E., Neumann, G.A., Smith, D.E., Torrence, M.H., Zuber, M.T., 2011. Global surface slopes and roughness of the Moon from the Lunar Orbiter Laser Altimeter. J. Geophys. Res. 116, E02001, doi:10.1029/2010JE003716 
1471

1472

1473

1474

1475

1476

1477

1478

1479

1480

1481

1482

1483

1484

1485

1486

1487

1488

1489

1490

1491

1492

1493

1494

1495

1496

1497

1498

1499

1500

1501

1502

1503

1504

1505

1506

1507

1508

1509

1510

1511

1512

1513

1514

1515

1516

1517

1518

1519

1520
Rutherford, M.J., Head, J.W., Saal, A.E., Hauri, E., Wilson, L., 2017. Model for the origin, ascent and eruption of lunar picritic magmas. Amer Mineral 102, 20452053, doi:10.2138/am-2017-5994ccbyncnd

Schultz, P.H., 1976. Moon Morphology: Interpretations Based on Lunar Orbiter Photography, University of Texas Press, Austin, 626 pp.

Schultz, P., Greeley, R., Gault, D., 1976. Degradation of small mare surface features, Lunar and Planetary Science Conference Proceedings VII, 985-1003.

Self, S., Thordarson, Th., Keszthelyi, L., Walker, G.P.L., Hon, K., Muphy, M.T., Long, P., Finnemore, S., 1996. A new model for the emplacement of Columbia River basalts as large, inflated pahoehoe lava flow fields. Geophys. Res. Lett. 23(19), 2689-2692.

Self, S., Keszthelyi, L., Thordarson, T., 1998. The importance of pahoehoe. Annual Rev. Earth Planet. Sci. 26, 81-110, doi:10.1146/annurev.earth.26.1.81

Sigmarsson, O., Thordarson, T., Jakobsson, S.P., 2009. Segregations in Surtsey lavas (Iceland) reveal extreme magma differentiation during late stage flow emplacement. In Studies in Volcanology: The Legacy of George Walker. Thordarson, T., Self, S., Larsen, G., Rowland, S. K. \& Hoskuldsson, A. (eds) Special Publications of IAVCEI, 2, 85-104.

Sisson, T.W., Bacon, C.R., 1999. Gas-driven filter pressing in magmas. Geology 27(7), 613-616.

Skelland, A.H.P., 1967. Non-Newtonian flow and heat transfer. John Wiley and Sons, New York, 469 pp.

Smith, D.E., Zuber, M.T., Neumann, G.A., Lemoine, F.G., Mazarico, E., Torrence, M.H., McGarry, J.F., Rowlands, D.D., Head, J.W., Duxbury, T.H., Aharonson, O., Lucey, P.G., Robinson, M.S., Barnouin, O.S., Cavanaugh, J.F., Sun, X., Liiva, P., Mao, D., Smith, J.C., Bartels, A.E., 2010. Initial observations from the Lunar Orbiter Laser Altimeter (LOLA). Geophys. Res. Lett. 37, L18204, doi: 10.1029/2010GL043751

Spudis P.D., 2015. Volcanism on the Moon. In Encyclopedia of Volcanoes, 2nd Edition, Sigurdsson H. et al., eds., Academic Press, New York, 689-700.

Suckale, J., Hager, B.H., Elkins-Tanton, L.T., Nave, J.-C., 2010. It takes three to tango: 2. Bubble dynamics in basaltic volcanoes and ramifications for modeling normal strombolian activity. J. Geophys. Res. 115, B07410, doi:10.1029/2009JB006917

Thordarson, Th., Self, S., 1998. The Roza Member, Columbia River Basalt Group: a gigantic pahoehoe lava flow field formed by endogenous processes? J. Geophys. Res. 103 (B11), 27,411-27,445.

Turcotte, D.L., Schubert, G., 2002. Geodynamics. Cambridge Univ. Press, 275 pp . 
1521

1522

1523

1524

1525

1526

1527

1528

1529

1530

1531

1532

1533

1534

1535

1536

1537

1538

1539

1540

1541

1542

1543

1544

1545

1546

1547

1548

1549

1550

1551

1552

1553

1554

1555

1556

1557

1558

1559

1560

1561

1562

1563

1564

1565

1566

1567

1568

1569
Vye-Brown, C., Self, S., Barry, T.L., 2013. Architecture and emplacement of flood basalt flow fields: case studies from the Columbia River Basalt Group, NW USA. Bull. Volcanol. 75, 697, 21 pp.

Walker, G.P.L., 1991. Structure, and origin by injection of lava under surface crust, of tumuli, lava rises, lava-rise pits, and lava-inflation clefts in Hawaii. Bull. Volcanol. 53(7), 546-558, doi:10.1007/BF00298155

Williams, D.A., Fagents, S.A., Greeley, R., 2000. A reevaluation of the emplacement and erosional potential of turbulent, low-viscosity lavas on the Moon, J. Geophys. Res. 105, 20,189-20,206.

Wilson, L., Head, J.W., 1981. Ascent and eruption of basaltic magma on the Earth and Moon. J. Geophys. Res. 86 (B4), 2971-3001.

Wilson, L., Head, J.W., 1983. A comparison of volcanic eruption processes on Earth, Moon, Mars, Io and Venus. Nature 302 (5910), 663-669.

Wilson, L., Head, J.W., 2017a. Generation, ascent and eruption of magma on the Moon: new insights into source depths, magma supply, intrusions and effusive/explosive eruptions (Part 1: Theory). Icarus 283, 146-175, doi:10.1016/j.volgeores.2015.12.039

Wilson, L., Head, J.W., 2017b. Eruption of magmatic foams on the Moon: formation in the waning stages of dike emplacement events as an explanation of "Irregular Mare Patches". J. Volcanol. Geotherm. Res. 335, 113-127, doi:10.1016/j.volgeores.2017.02.009

Wilson, L., Head, J.W., 2018a. Controls on lunar basaltic volcanic eruption structure and morphology: Gas release patterns in sequential eruption phases. Geophys. Res. Lett. 45(12), 5852-5859, doi:10.1029/2018GL078327

Wilson, L., Head, J.W., 2018b. Lunar Basaltic Volcanic Eruptions: Gas Release Patterns and Variations in Lava Vesicularity: 2. Fissures Mare Flows, and Ring Moat Dome Structures (RMDS) Morphology. Lunar and Planetary Science XLIX, abstract \#1326.

Zhang, F., Head, J.W., Basilevsky, A.T., Bugiolacchi, R., Komatsu, G., Wilson, L., Fa, W., Zhu, M.-H., 2017. Newly discovered ring-moat dome structures in the lunar maria: possible origins and implications. Geophys. Res. Lett. 44(18), 9216-9224, doi:10.1002/2017GL074416

Zhang, F., Wöhler, C., Head, J.W., Bugiolacchi, R., Wilson, L., Grumpe, A., 2018a. Ring-Moat Dome Structures (RMDS) in the lunar maria: further statistical and morphological characterization. Lunar and Planetary Science XLIX, abstract \#1374.

Zhang, F., Wöhler, C., Head, J.W., Bugiolacchi, R., Wilson, L., Grumpe, A., 2018b. Ring-Moat Dome Structures (RMDS) in the lunar maria: morphological diversity 
1570 and comparison to Irregular Mare Patches. Asia Oceania Geosciences Society

1571 (AOGS), Honolulu, Hawaii, Abstract (PS11-A026).

1572

1573

1574 

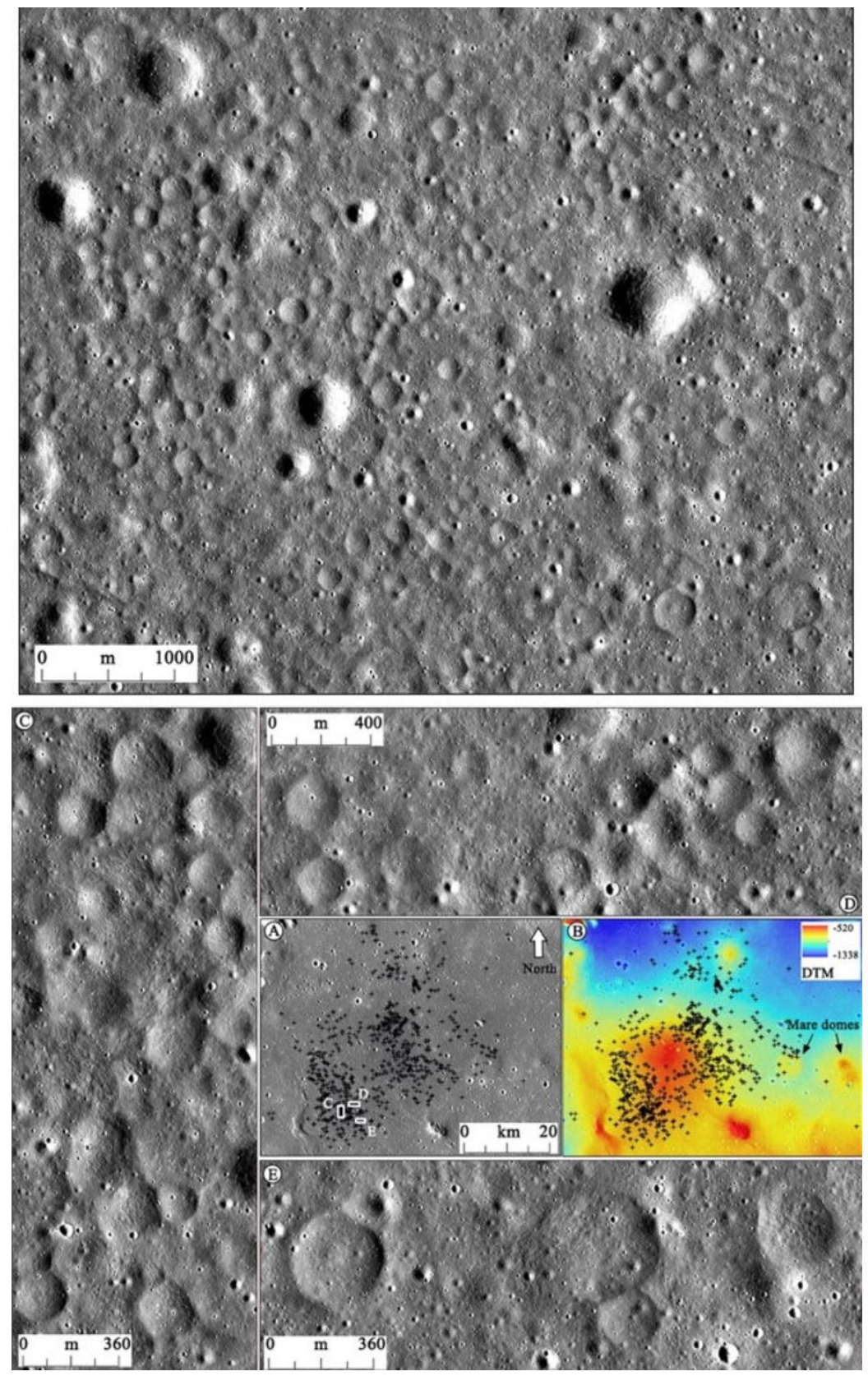

1579 Figure 1. Ring Moat Dome Structures (RMDS). North is up in all images. The sun 1580 illumination direction is from left to right. Top: LROC NAC mosaic (frames 1581 M1096293859LE and RE) showing a dense distribution $\left(\sim 30.8^{\circ} \mathrm{E}, 10.3^{\circ} \mathrm{N}\right)$ of RMDSs 1582 in Mare Tranquillitatis. Bottom: LROC WAC mosaic (A) and Kaguya TC-derived 1583 DTM (B) of a ring moat dome structure (RMDS) terrain (Coordinates of the figure 1584 center: $\left.\sim 31.4^{\circ} \mathrm{E}, 11.0^{\circ} \mathrm{N}\right)$ in Mare Tranquillitatis. Enlarged views (C, D, and E) of RMDSs in LROC NAC mosaic (frames M1096293859LE and RE) and their locations (white boxes) are shown in Figure 1 bottom, A. Reproduced from Zhang et al. (2017), with permission, ( $)$ John Wiley and Sons/American Geophysical Union. 
(a)

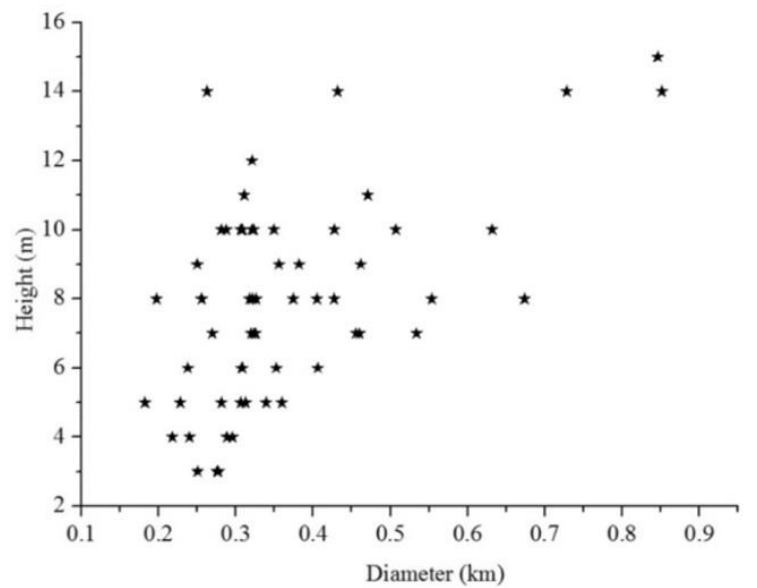

(b)

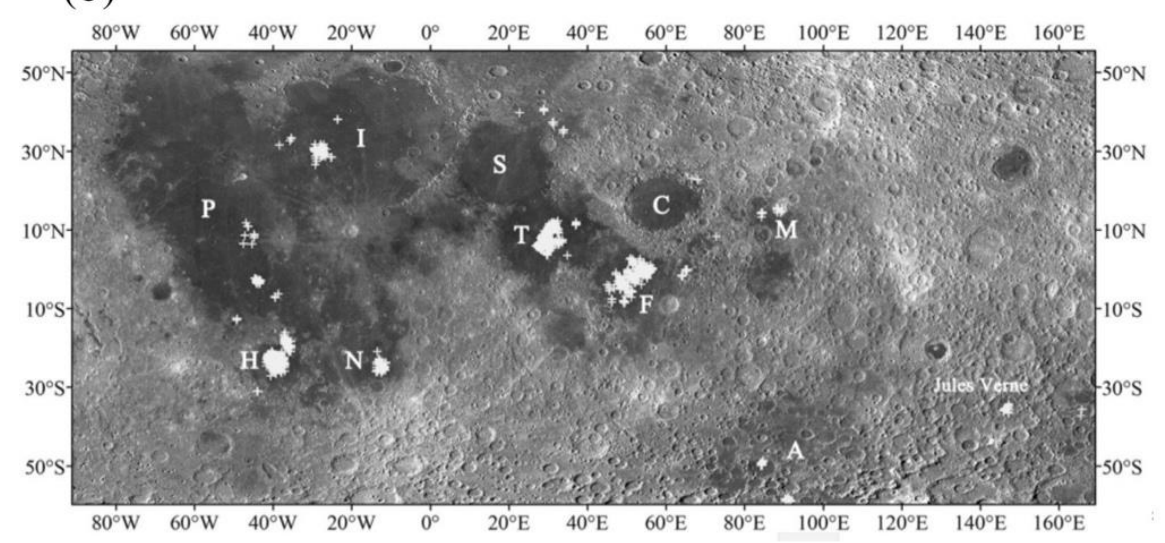

(c)

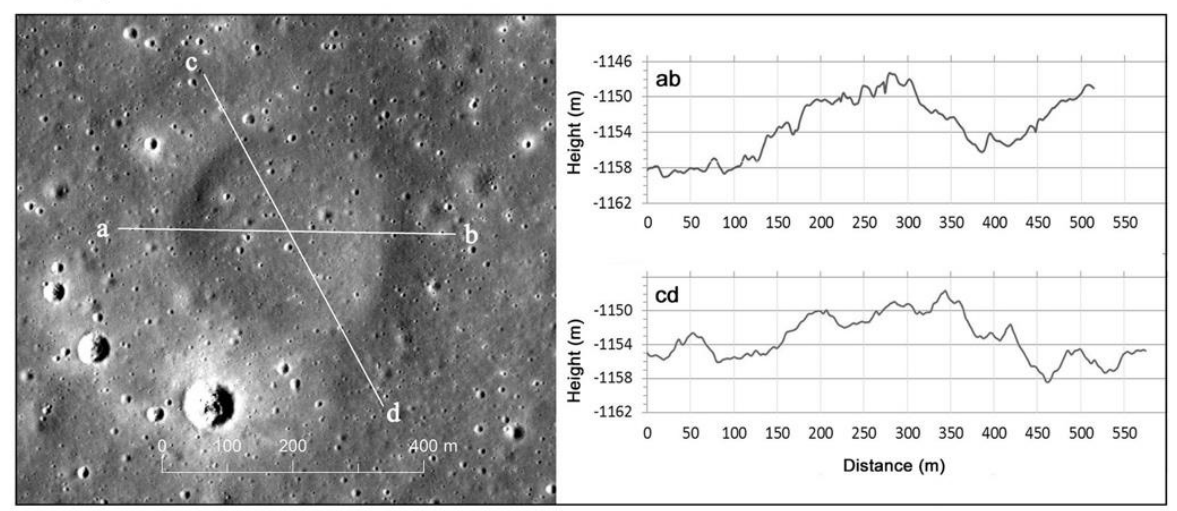

1592 Figure 2. (a) Diameter versus height of 60 RMDSs in Mare Tranquillitatis measured from Kaguya-TC derived DTMs (Zhang et al. 2017). (b) LROC WAC mosaic showing the distribution of about 2,600 RMDSs (white crosses) identified in the lunar maria. Imbrium (I), Serenitatis (S), Crisium (C), Tranquillitatis (T), Fecunditatis (F), Humorum (H), Nubium (N), Marginis (M), Australe (A), and Oceanus Procellarum (P) are labeled. Reproduced from Zhang et al. (2017), with permission, (C) John Wiley and Sons/American Geophysical Union. (c) Cross-sectional profiles of an RMDS that is about $400 \mathrm{~m}$ in diameter located at $10.579^{\circ} \mathrm{N}, 30.689^{\circ} \mathrm{E}$, LROC NAC image. 
1602

1603

1604

1605

1606

1607

1608

1609

1610

1611

1612

1613

1614

1615

1616

1617

1618

1619

1620

1621

1622

1623

1624

1625

1626

1627

1628

1629
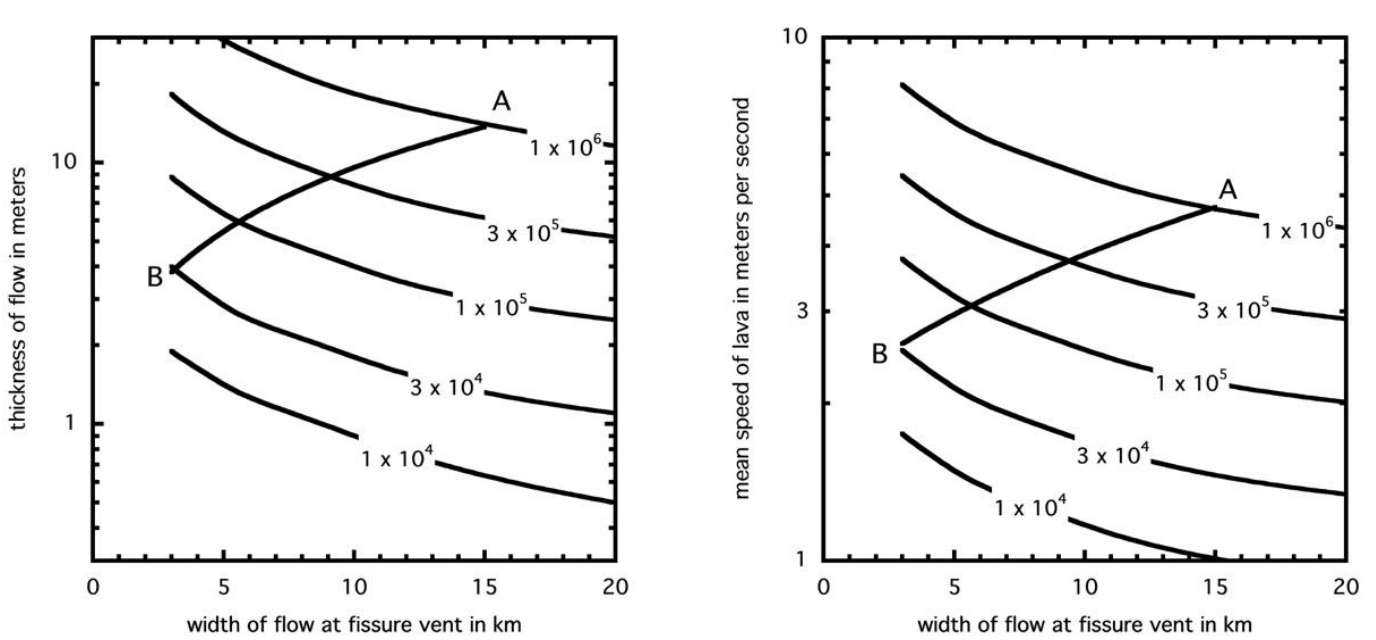

Figure 3. Variation of (a) thickness and (b) mean flow speed of a lunar mare lava flow as a function of the length along strike of the fissure feeding the flow and the dense rock equivalent volume flux, $F$, being erupted - curves labelled in $\mathrm{m}^{3} \mathrm{~s}^{-1}$. Label $\mathrm{A}$ indicates conditions in the early stage of the eruption and corresponds to lava that forms the distal part of the resulting flow field; label B indicates conditions in the late stage of the eruption and corresponds to lava forming the proximal deposits. Flows are turbulent for all $F$ greater than $\sim 3 \times 10^{4} \mathrm{~m}^{3} \mathrm{~s}^{-1}$ and remain so until $F$ decreases below this value. When $F$ becomes less than $\sim 2 \times 10^{4} \mathrm{~m}^{3} \mathrm{~s}^{-1}$, the explosive activity at the vent changes from hawaiian to strombolian. At all stages these flows contain a non-zero volume fraction of solids and are treated as Bingham plastics, not Newtonian fluids.
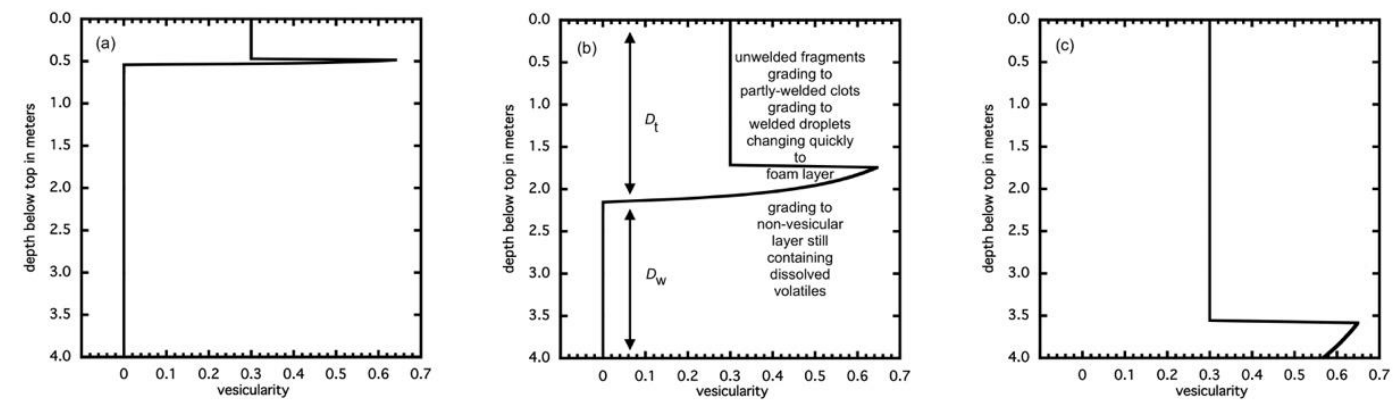

Figure 4. Variation of vesicularity with depth in 4 meter thick proximal lunar mare lava flows. Parts (a), (b) and (c) correspond to total water contents in the erupted lava of 100, 200 and 300 ppm, respectively. In parts (a) and (b) a layer of disaggregated lava overlies a very vesicular layer, which in turn overlies a vesicle-free layer still containing dissolved water. In part (c) no part of the flow retains any dissolved water. The text within part (b) describes the successive changes that occur with depth in the flow. 
1630

1631

1632

1633

1634

1635

1636

1637

1638

1639

1640

1641

1642

1643

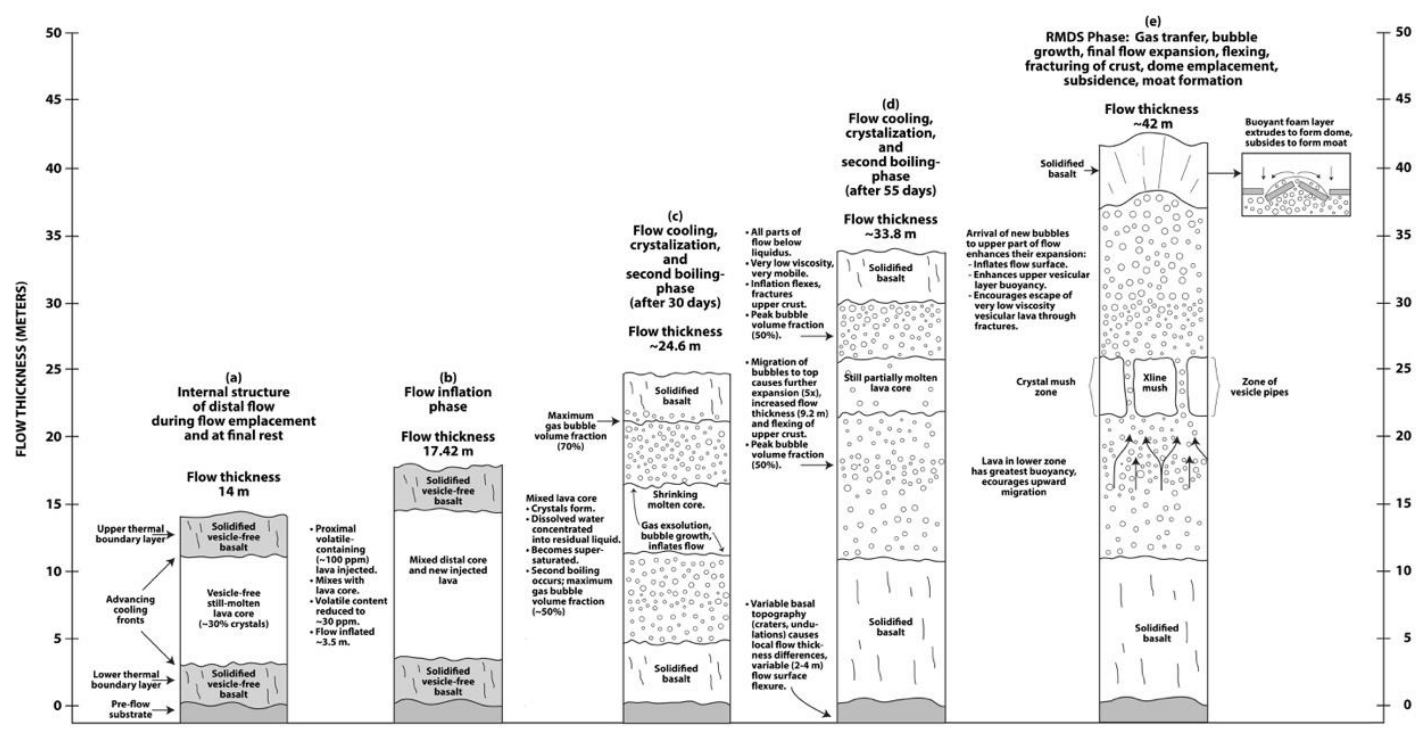

Figure 5. Five stages in the internal structure of a distal flow during the final stages of flow emplacement, at final rest, and following further flow cooling and second boiling for the cases where late stage lava flows have $<\sim 280 \mathrm{ppm}$ volatile content (compare with Figure 6). (a) Internal structure of distal flow during flow emplacement and at final rest. (b) Flow inflation phase. (c) Flow cooling, crystallization and second boiling phase (after 30 days). (d) Flow cooling, crystallization and second boiling phase (after 55 days). (e) RMDS phase: gas transfer, bubble growth, final flow expansion, flexing, fracturing of crust, dome emplacement, subsidence, and moat formation. 

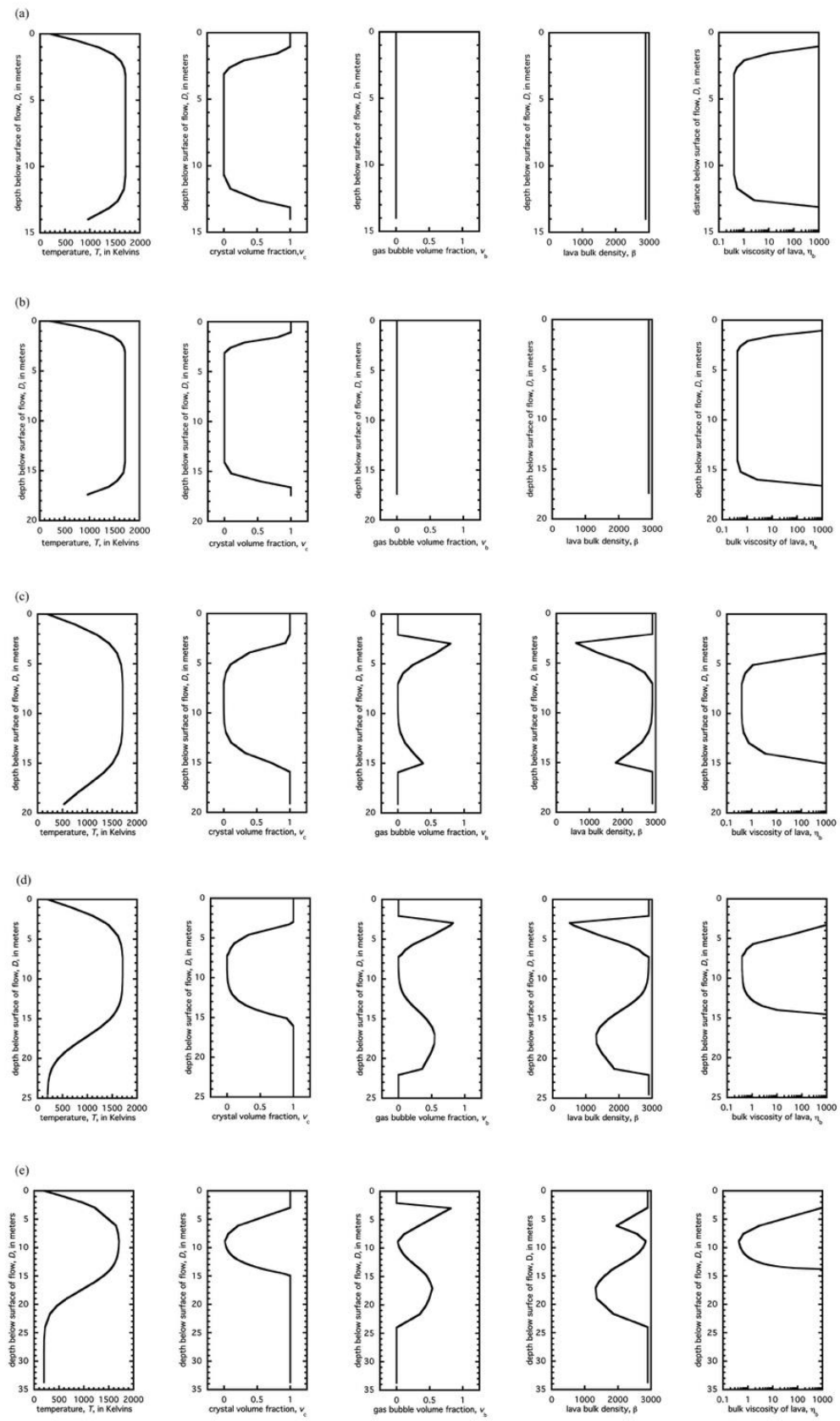

Figure 6. Variation as a function of depth in a distal lunar mare lava flow of the temperature, crystal volume fraction, gas bubble volume fraction, bulk density, and bulk viscosity. Parts (a) and (b) represent conditions just before, and just after, respectively, proximal lava containing dissolved volatiles is injected into a distal, volatile-free flow. Parts (c), (d) and (e) correspond to time intervals of 20, 40 and 55 days, respectively, after the lower 3.42 meters of a proximal flow containing $100 \mathrm{ppm}$ water is injected into a $14 \mathrm{~m}$ thick distal flow. Note the changing vertical scale due to the progressive inflation of the flow as increasing amounts of water are forced out of solution by second boiling due to the increasing crystal content as the interior of the flow cools. 


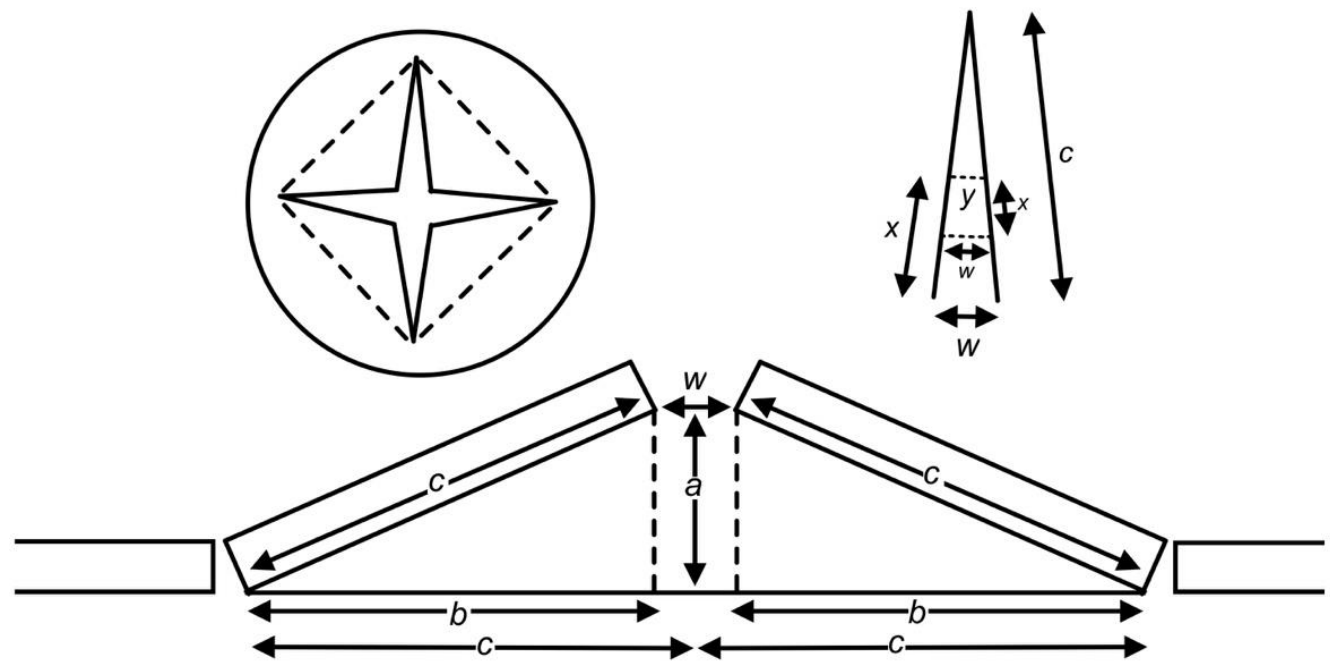

1660

1661

1662

1663

1664

1665

1666

1667

1668

1669

1670

1671

1672

1673

1674

1675

1676

1677
Figure 7. Sketches of the geometry of the fracturing and uplift of a mare lava flow surface crust as foam becomes concentrated beneath the upper crust of the flow. For simplicity it is assumed that four orthogonal fractures form. Upper row: plan view; lower row: cross-section. Variables are defined and discussed in the text.
(A)

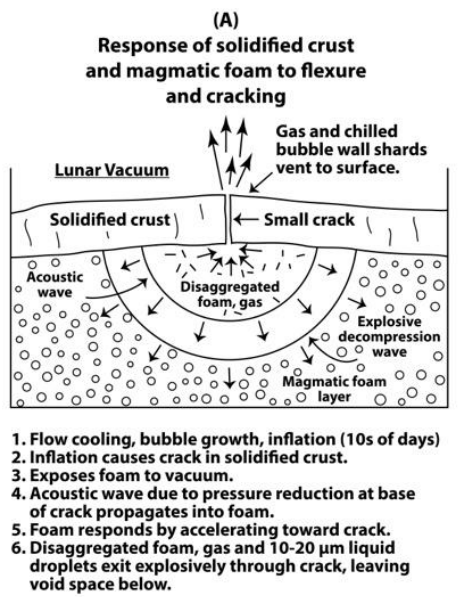

(B)

Redistribution of foam

to fill void space

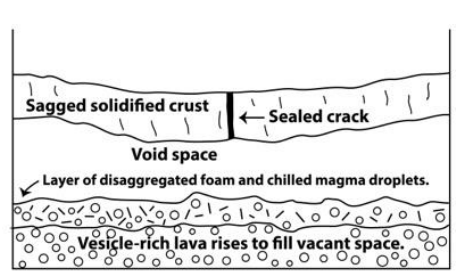

1. Small crack sealed by hot magma droplets and 1. Small crack sealed by hot magma droplets and
cooled bubble wall shards.
2. Crack sealing inhibits wholesale collapse; crust sags, but remains coherent.
3. Void space filled by rising vesicular magma.
(C)

Initial stage in Ring-Moat Dome Structure (RMDS) emplacement

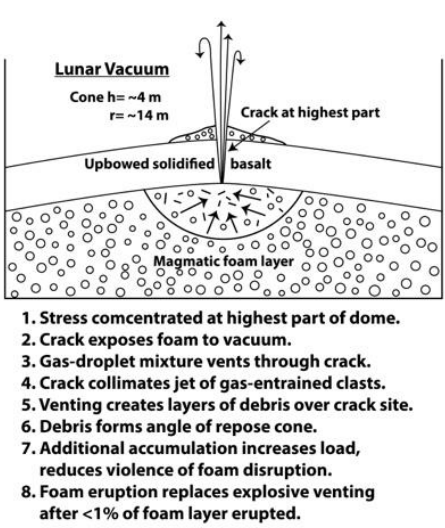

Figure 8. Behavior of magmatic foam when cracks form in the solidified lava crust and the magmatic foam is exposed to the lunar surface vacuum. (A) Upper inflated flow configuration (see Figure 5e for context) and consequences when cracks form in the upper cooled upper flow boundary layer. (B) Initial venting of gas/foam and creation of potential void space filled by accumulating foam from lower in the flow. (C) Venting of foams to form ring-moat dome structures (RMDS). 
1678

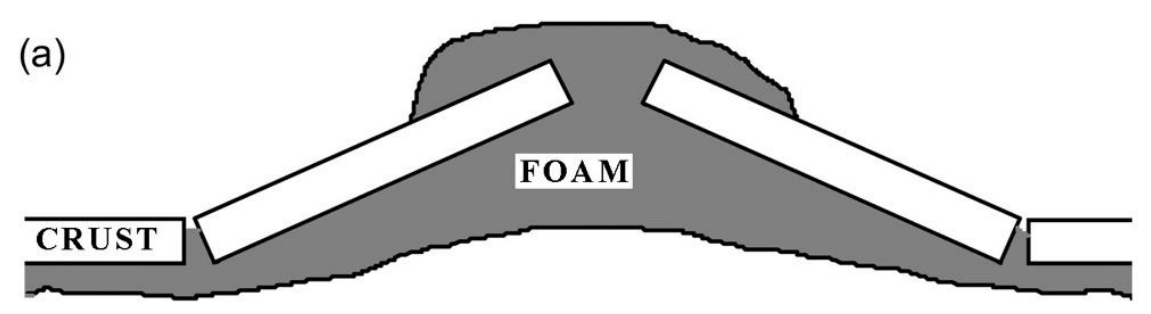

LAVA
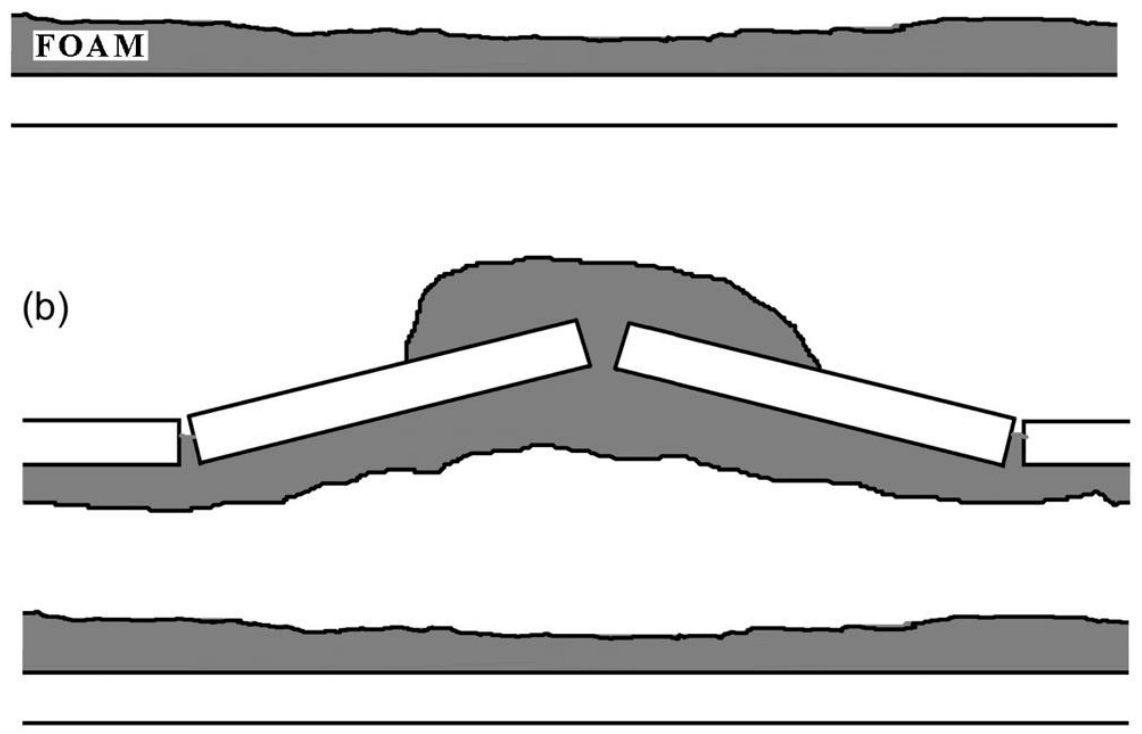

(c)
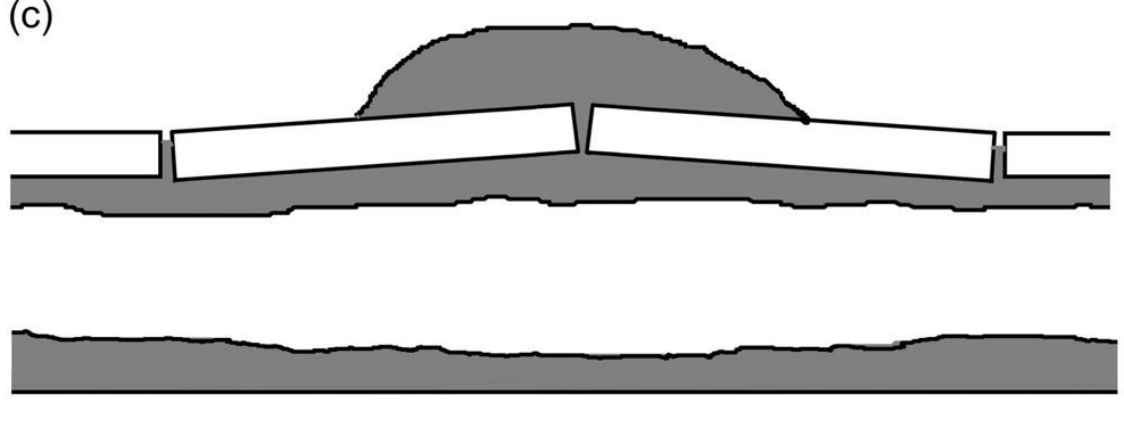

1681 Figure 9. A possible scenario for the progressive stages of collapse of the geometry of Figure 7 as foam is extruded through the cracks. This configuration would shut off the foam release too quickly and is not favored - see Figure 10. Vertical exaggeration $\sim 20$. 


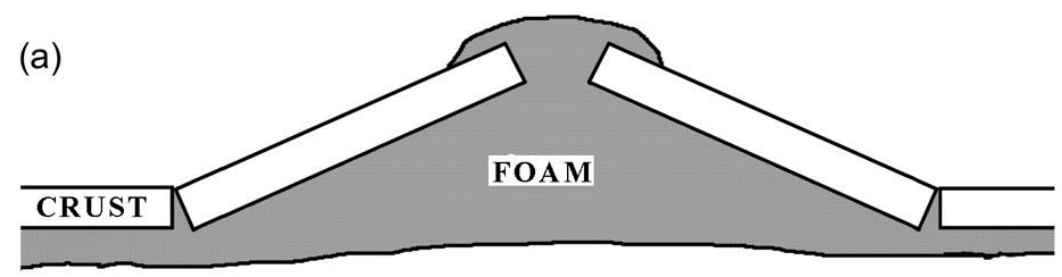

\section{LAVA}

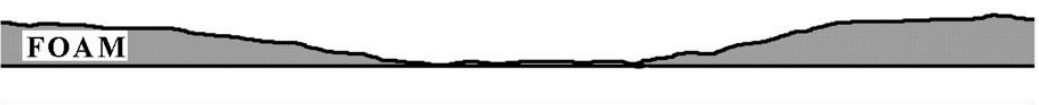

(b)
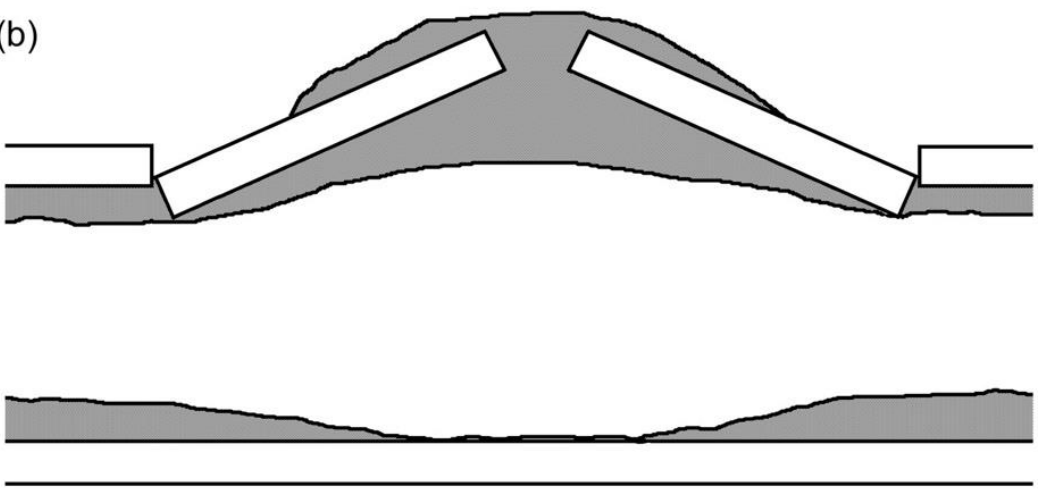

(c)
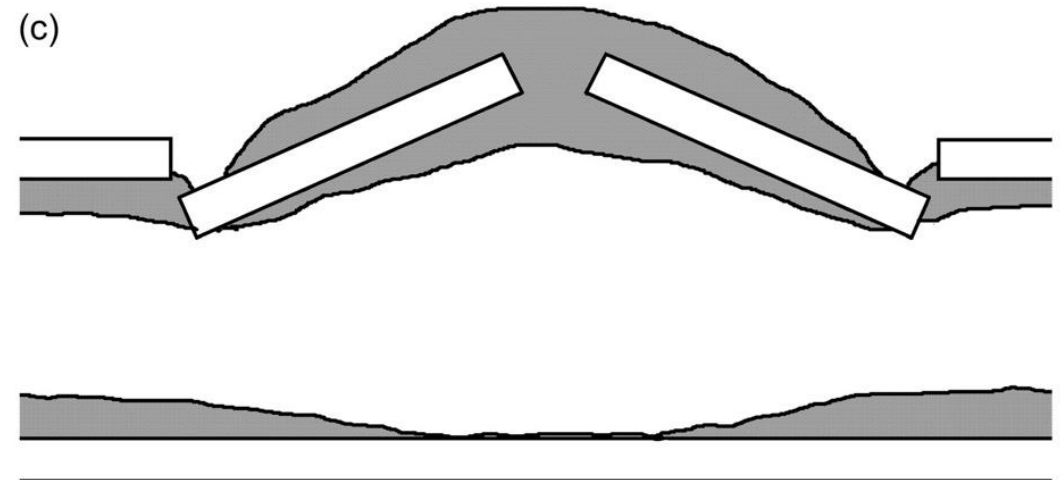

Figure 10. Preferred scenario for the progressive stages of RMDS foam emplacement and moat formation on the basis of the general geometry shown in Figure 7. (a) Foam (shown in grey) upwells from lower foam layer to upper foam layer, causing upbowing and cracking of brittle crust, and begins extrusion through cracks in the lava crust. (b) Subsidence of the crustal slabs maximizes both the rate and volume of the foam released. (c) Note the progressive production of a moat at the edge of the mound by this pattern of subsidence. See Figure 5 for the sequence of events leading up to this final stage. Vertical exaggeration $\sim 20 \mathrm{x}$. 


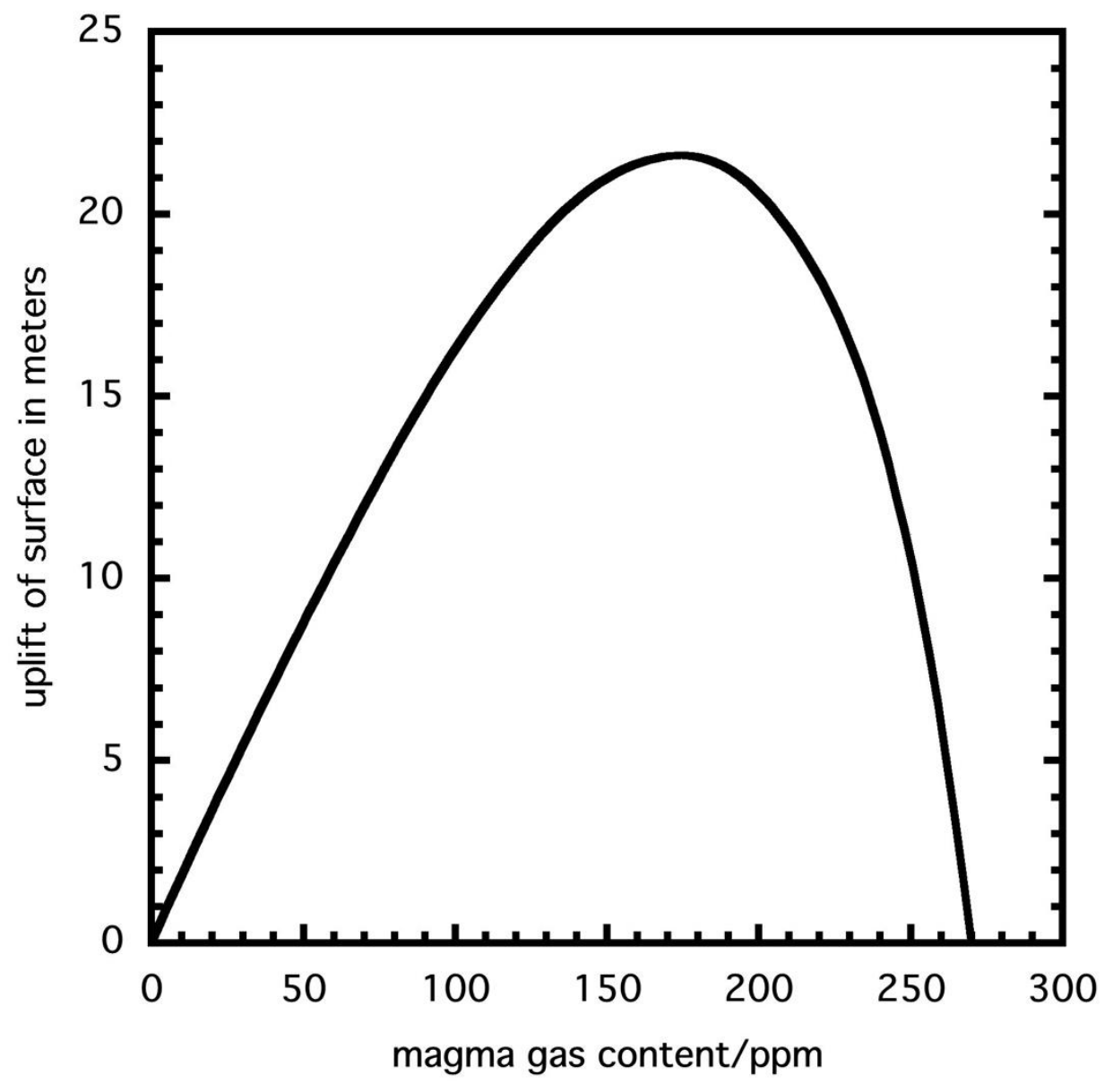

Figure 11. Uplift of the surface of a stationary lava flow by gas released when cooling induces second boiling in lava injected into the stationary flow by continuing activity at the vent. The uplift is given as a function of the dissolved gas mass fraction in the injected lava.

1705

1706 


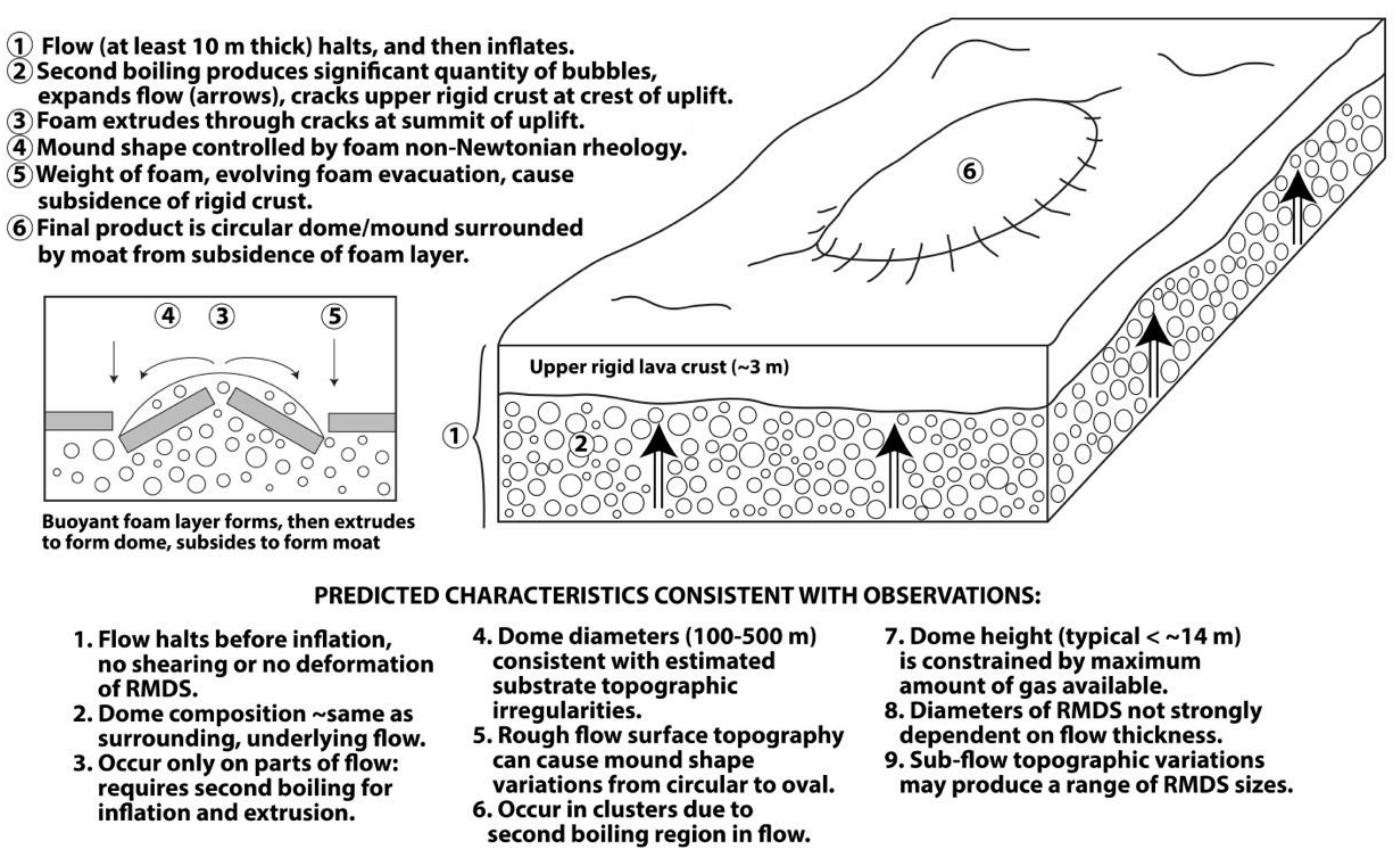

1710 Figure 12. Illustration of the proposed model for Ring Moat Dome Structure (RMDS)

1711 formation due to flow inflation and second boiling. Perspective and cross-sectional

1712 views illustrate the main steps following cessation of injection of lava with dissolved

1713 volatiles that inflates the core of the initially emplaced flow: flow cooling, second

1714 boiling, foam formation, flow inflation, rigid crust cracking and foam extrusion to

1715 form RMDS. Predicted RMDS characteristics that are consistent with observations

1716 (Zhang et al., 2017; 2018a) are listed. See Figure 5 for steps in flow emplacement

1717 leading up to these final stages of RMDS formation. 
(b)
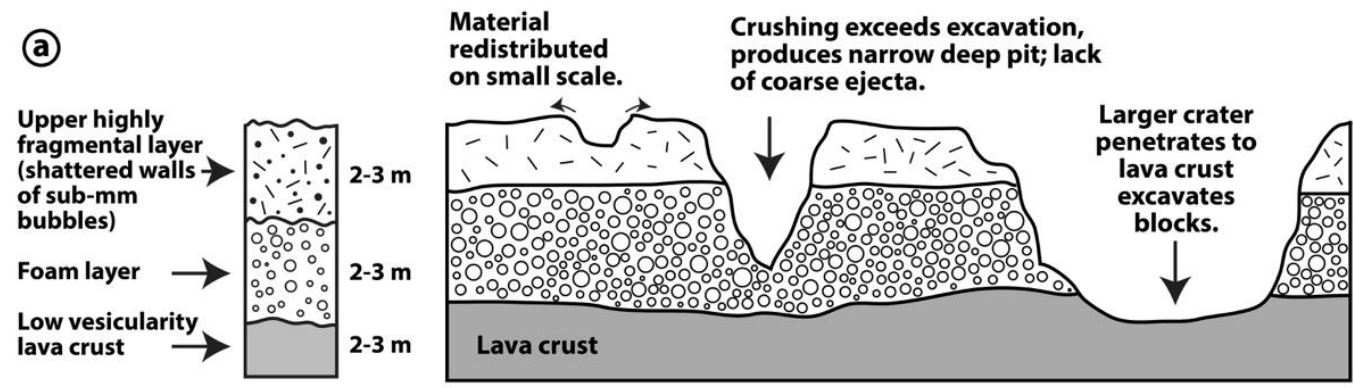

Initial post-dome emplacement cratering influenced by vertical target structure. Dome/mound surface: Coarse ejecta scarce, vesicular/low density material yields low-strength radar return, thermal anomalies. Initial differences smoothed out with impact regolith development.

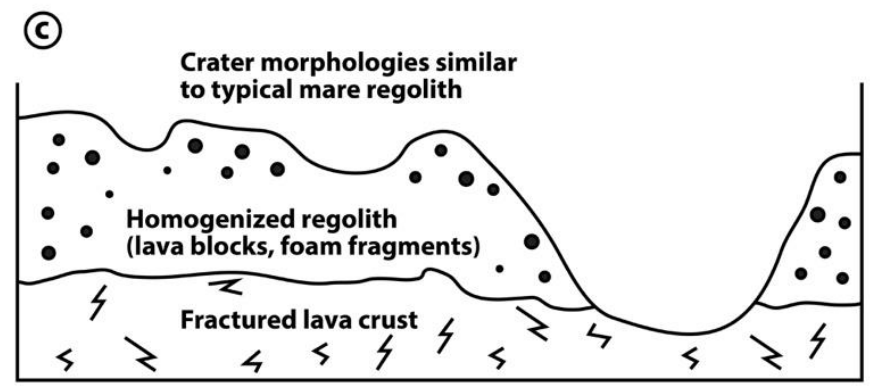

1720

1721

1722

1723

1724

1725

1726

1727

1728

1729

1730

1731

1732

1733

1734

1735

1736

1737

1738

1739

1740

1741

1742

1743

1744

Figure 13. Cross-sectional views of an RMDS dome segment illustrating the change in physical properties as a function of time, and the response of these evolving target properties to the subsequent impact events that are building the regolith. (a) The initial vertical column consists of an upper part of an RMDS dome, illustrating the three predicted layers (1-shattered foam bubble walls; 2-foam layer; 3-uplifted solid lava crust). (b) Initial and early ( 1-10 Ma) regolith development, in which small craters (left) simply redistribute the upper 2-3 m thick highly fragmental layer, larger craters (middle) penetrate into the 2-3 m thick foam layer and produce deeper, narrower craters due to crushing of foam, and even larger craters (right), penetrate to the solidified lava crust below and can excavate blocks of the uplifted solid lava crust (see Figures 10 and 12). (c) Later-stage regolith development (>10-1000 Ma) in which impacts superposed in the intervening period have tended to homogenize the initial differences in physical properties ( $\mathrm{a}$ and $\mathrm{b}$ ) and to produce a regolith and superposed crater morphologies that are very similar to those being developed on adjacent, non-RMDS maria. These evolutionary responses of superposed craters to regolith development may influence the impact crater size-frequency distribution, and thus inferred ages, of RMDS features relative to non-RMDS maria. In situ samples of mature RMDS regolith soils are predicted to have a much higher abundance of shattered walls of sub-mm bubbles and fine foam fragments than typical non-RMDS regolith (Head and Wilson, 2019). 